\title{
Isabela Saldanha Fortes
}

Prevalência de transtornos específicos de aprendizagem e sua associação com transtornos mentais da infância e adolescência do Estudo Epidemiológico de Saúde Mental do Escolar Brasileiro - INPD

Dissertação apresentada à Faculdade de Medicina da Universidade de São Paulo para obtenção do título de Mestre em Ciências

Programa de Psiquiatria

Orientador: Luis Augusto Paim Rohde

(Versão corrigida. Resolução CoPGr 6018/11, de 13 de outubro de 2011. A versão original está disponível na Biblioteca da FMUSP)

São Paulo 
Dados Internacionais de Catalogação na Publicação (CIP)

Preparada pela Biblioteca da

Faculdade de Medicina da Universidade de São Paulo

Creprodução autorizada pelo autor

\section{Fortes, Isabela Saldanha}

Prevalência de transtornos específicos de aprendizagem e sua associação com transtornos mentais da infância e adolescência do Estudo Epidemiológico de Saúde Mental do Escolar Brasileiro - INPD / Isabela Saldanha Fortes. -- São Paulo, 2014.

Dissertação(mestrado)--Faculdade de Medicina da Universidade de São Paulo. Programa de Psiquiatria.

Orientador: Luis Augusto Paim Rohde.

Descritores: 1.Transtornos de aprendizagem 2.Transtornos mentais 3.Estudos transversais 4.Prevalência 5.Criança 6.Adolescente 7. Comorbidade 8.Manual diagnóstico e estatístico de transtornos mentais

USP/FM/DBD-444/14 
Ao querido e eterno Mercadante, por tudo que me ensinou em vida e que me permitiu vivenciar e dar continuidade após a sua passagem. Sua estrela brilha pra sempre! 


\section{Agradecimentos}

À minha família, base principal da minha vida, pelo amor e apoio sem fim: à minha mãe Sandra, por ser sempre tão guerreira e ter me transmitido um pouco dessa garra, além de toda ajuda, mesmo nos momentos mais delicados da sua vida; ao meu pai Luiz Paulo, por todo suporte, sendo este na área acadêmica ou pessoal, que com certeza me ajudou e muito para que eu chegasse até aqui; e à minha irmã Luciana, minha companheira de todas as horas, por ser meu racional quando precisei e pelas gargalhadas intermináveis, na alegria e na tristeza.

Ao Mercadante, por ter aberto as portas para que todo esse processo fosse possível de acontecer.

Ao Rohde, por ter sido o melhor orientador que eu poderia ter após a perda de uma pessoa tão querida. Obrigada por todas as orientações quando precisei, assim como os esclarecimentos de todas as minhas dúvidas, sempre tão prontamente.

Ao Prof. Euri, agradeço de coração, por ter me acolhido quando realmente precisei e por todo aprendizado científico durante estes anos da minha jornada acadêmica.

À toda minha família Saldanha e Fortes e especialmente aos meus avós Maria Regina e Francisco, aos meus tios Cláudio, Helena e Alex, e ao meu primo Henrique por terem acompanhado de perto todo o processo e por me incentivarem a continuar em frente sempre, mesmo diante de pedras no caminho.

Ao meu eternamente amado Vovô Paulo, e à querida Vovó Rosa, por todas vibrações positivas e sempre de muito amor. Mesmo de longe, sempre estiveram tão perto. 
Ao querido Jair, por me apoiar nessa minha jornada acadêmica desde o início, agradeço por me apresentar à pessoa que se tornou uma das mais especiais que conheci nessa vida!

Às crianças, que são minha maior fonte de inspiração e motivação para o aprendizado e mudança.

À Mel, por todo apoio de sempre com a estatística.

À equipe da Multifocus, pela parceria sempre presente durante todo projeto.

Às queridas Eliza e Isabel, Geysa, Fátima, por toda atenção, paciência e ajuda, sempre atendida.

À Carol D’Angelino, pelas orientações e suporte, assim como pela amizade e carinho construídos.

À CAPES, CNPq e FAPESP, pela oportunidade e investimento para realização deste trabalho. 
Esta dissertação ou tese está de acordo com as seguintes normas, em vigor no momento desta publicação:

Referências: adaptado de International Committee of Medical Journals Editors (Vancouver).

Universidade de São Paulo. Faculdade de Medicina. Divisão de Biblioteca e Documentação. Guia de apresentação de dissertações, teses e monografias. Elaborado por Anneliese Carneiro da Cunha, Maria Julia de A. L. Freddi, Maria F. Crestana, Marinalva de Souza Aragão, Suely Campos Cardoso, Valéria Vilhena. 3a ed. São Paulo: Divisão de Biblioteca e Documentação; 2011.

Abreviaturas dos títulos dos periódicos de acordo com List of Journals Indexed in Index Medicus. 


\section{Sumário}

Lista de Abreviaturas

Lista de Figuras

Lista de Tabelas

Resumo

Abstract

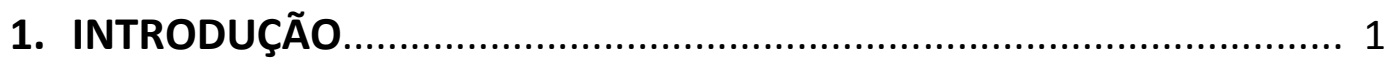

1.1 Visão geral da aprendizagem................................................. 1

1.2 Diferentes conceitos de problemas de aprendizagem...................... 2

1.2.1 Dificuldade de aprendizagem............................................. 3

1.2.2 Transtorno de aprendizagem........................................... 4

1.3 Diagnósticos de transtorno de aprendizagem na CID-10 e em diferentes versões da DSM: DSM-IV x DSM-5............................... 4

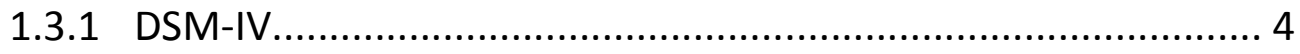

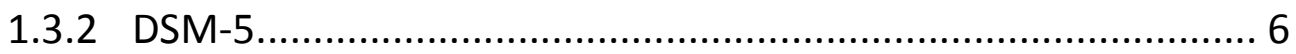

1.4 Transtorno específico de aprendizagem...................................... 8

1.4.1 Impacto na sociedade .................................................... 9

1.4.2 Estudos de prevalência.................................................... 10

1.5 Comorbidades......................................................................... 12

1.5.1 Estudos de prevalência..................................................... 13

1.6 Justificativa..................................................................... 13

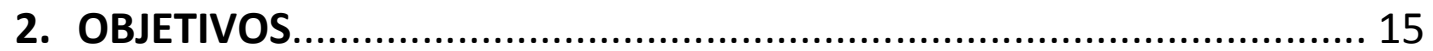

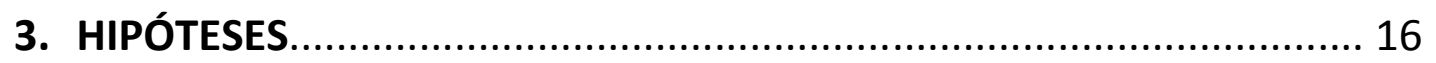

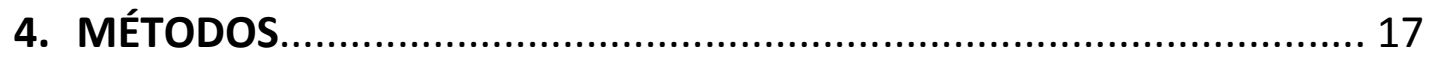


4.1 Antecedentes - Estudo principal................................................ 17

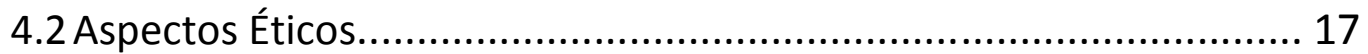

4.3 Desenho do Estudo....................................................................... 18

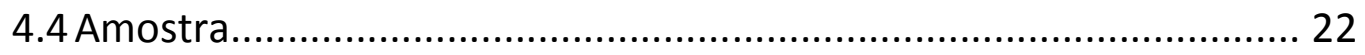

4.4.1 Critérios de Inclusão......................................................... 22

4.4.2 Critérios de Exclusão........................................................ 22

4.5 Instrumentos de avaliação e treinamento................................. 22

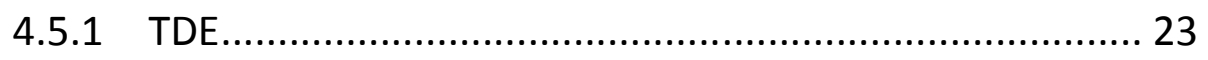

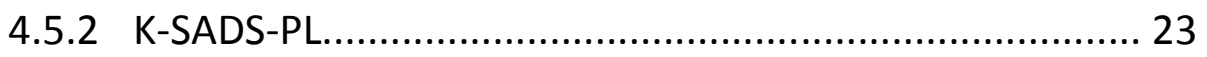

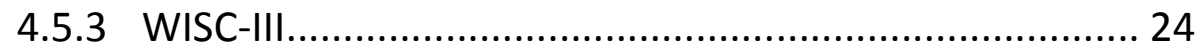

4.5.4 Questionário Sócio-econômico e de Fatores de Risco e Proteção............................................................................ 25

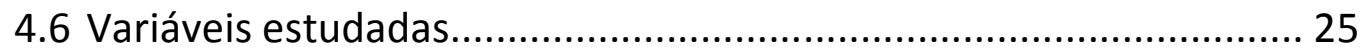

4.6.1 Diagnósticos Psiquiátricos................................................ 25

4.6.2 Transtorno Específico de Aprendizagem............................. 26

4.6.3 Triagem para deficiência intelectual.................................... 27

4.6.4 Investigação de correlatos sócio-demográficos.................. 27

4.6.5 Variáveis de confusão........................................................ 27

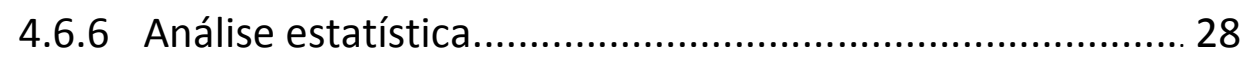

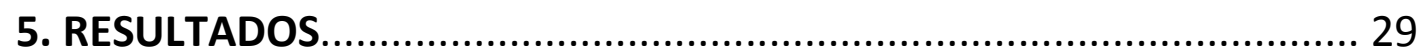

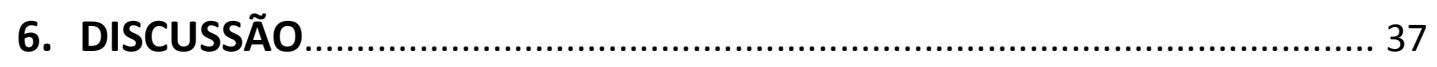

6.1 Similaridade e diferenças dos achados de prevalência com

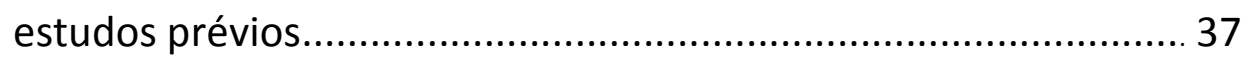

6.1.1 Transtorno de Aprendizagem.............................................. 37

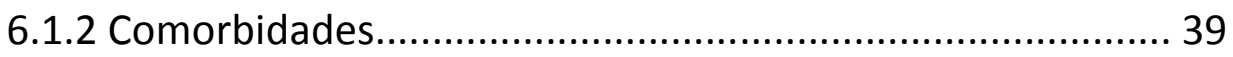


6.2 Similaridade e diferenças dos achados de correlatos com estudos prévios.

6.3 Comparação das prevalências de acordo com definições do DSMIV e DSM-5

6.4 “Normas Brasileiras" ......................................................... 42

6.5 Limitações.................................................................... 43

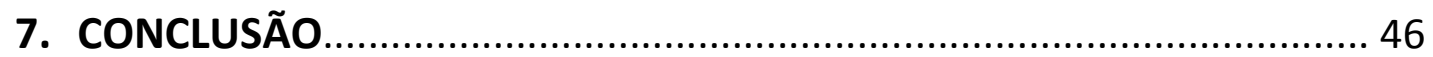

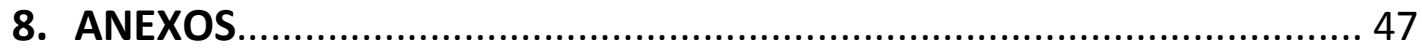

Anexo A: Escolas do Brasil........................................................ 47

Anexo B: Termo de consentimento............................................... 49

Anexo C: Indivíduos com TEA: DSM-IV x DSM-5 .......................... 51

Anexo D: Tabela complementar de QI: perfil por cidade................. 53

Anexo E: Tabela TDE............................................................. 54

Anexo F: Questionário sócio-econômico e de fatores de risco e proteção.............................................................................. 55

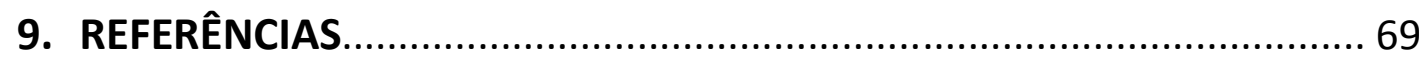




\section{Lista de abreviaturas}

CAPES

$\mathrm{CNPq}$

DP

DSM

DSM-IV

DSM-5

IDH

INPD

K-SADS

K-SADS-PL

LMIC

PBMR

QI

SSE

TDAH

TDE

TEA

RTI

WISC-III
Coordenação de Aperfeiçoamento de Pessoal de Nível Superior

Conselho Nacional de Desenvolvimento Científico e Tecnológico

Desvio-padrão

Manual Diagnóstico e Estatístico dos Transtornos Mentais

Manual Diagnóstico e Estatístico dos Transtornos Mentais - $4^{\mathrm{a}}$ edição

Manual Diagnóstico e Estatístico dos Transtornos Mentais - 5 edição

Índice de Desenvolvimento Humano

Instituto Nacional de Psiquiatria do Desenvolvimento

Schedule for Affective Disorders and Schizophrenia for School-Age Children

Schedule for Affective Disorders and Schizophrenia for School-Age Children - Present and Lifetime Version

Low and Middle Income Countries

Países de baixa e média renda

Quociente de Inteligência

Status sócio-econômico

Transtorno de Déficit de Atenção e Hiperatividade

Teste de Desempenho Acadêmico

Transtorno Específico de Aprendizagem

Resposta à Intervenção

Escala de Inteligência Wechsler para Crianças Terceira Edição 


\section{Lista de Figuras}

Figura 1 - Classificação dos Transtornos de Aprendizagem de acordo com o

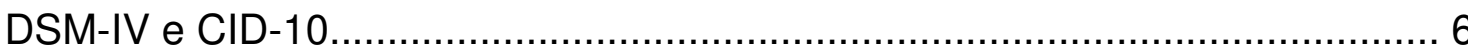

Figura 2 - Amostra, Recrutamento e Seleção.............................................. 21 


\section{Lista de Tabelas}

Tabela 1 - Prevalência de transtorno específico de aprendizagem com comprometimento global assim como na escrita, aritmética, e leitura 30

Tabela 2 - Prevalência de Comorbidades em Crianças e Adolescentes com TEA.

Tabela 3 - Correlatos para TEA com comprometimento global em um Modelo de Regressão Logística.

Tabela 4 - Comparação de prevalências entre os diferentes critérios diagnósticos do DSM-IV e DSM-5 para Transtorno Específico de Aprendizagem (TEA) de Crianças e Adolescentes.

Tabela 5 - Comparação de prevalências entre os diferentes critérios diagnósticos do DSM-5 e Normas Brasileiras para Transtorno Específico de Aprendizagem (TEA) de Crianças e Adolescentes 35

Tabela 6 - Número de estabelecimentos de ensino fundamental, total e em área urbana, por etapa e dependência administrativa, segundo as Grandes Regiões e as Unidades da Federação - 2012

Tabela 7 - Crianças e adolescentes com TEA com comprometimento global: DSM-IV x DSM-5. 51

Tabela 8 - Crianças e adolescentes com TEA com comprometimento na escrita: DSM-IV x DSM-5 
Tabela 9 - Crianças e adolescentes com TEA com comprometimento na

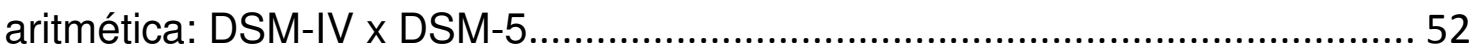

Tabela 10 - Crianças e adolescentes com TEA com comprometimento na

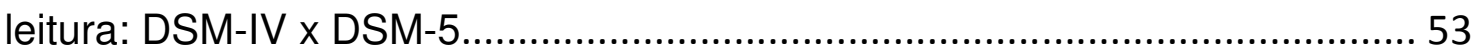

Tabela 11 - Média e desvio-padrão do QI por cidade........................................ 53

Tabela 12 - Média e desvio-padrão por ano escolar do TDE............................ 54 


\section{Resumo}

Fortes, I. S. Prevalência de transtornos específicos de aprendizagem e sua associação com transtornos mentais da infância e adolescência do Estudo Epidemiológico de Saúde Mental do Escolar Brasileiro - INPD [Dissertação]. São Paulo: Faculdade de Medicina, Universidade de São Paulo; 2014.

Introdução: Pouco se conhece sobre Transtorno Específico de Aprendizagem (TEA), principalmente em países de baixa e média renda (PBMR) e muito menos em amostras representativas de escolas de cidades pequenas fora de grandes centros urbanos. Poucos estudos enfatizaram os novos critérios do DSM-5 para TEA. Investigamos a prevalência do Transtorno Específico de Aprendizagem de acordo com a nova classificação do DSM-5, suas comorbidades e correlatos em amostras escolares de alunos do $2^{-}$ao $6^{\circ}$ ano que moram em cidades de tamanho médio de quatro regiões geográficas do Brasil (norte, nordeste, centro-oeste e sudeste).

Métodos: O rendimento acadêmico foi medido pelo Teste de Desempenho Escolar. Os diagnósticos psiquiátricos foram avaliados pelo K-SADS-PL com informações obtidas do cuidador primário e o QI foi estimado por subtestes do WISC-III.

Resultados: Um total de 1.618 crianças e adolescentes foram incluídas no estudo. As taxas de prevalência encontradas de Transtorno Específico de Aprendizagem foram: 7,6\% para comprometimento global, 5,4\% para comprometimento na escrita, 6,0\% para comprometimento na área da aritmética, e 7,5\% para comprometimento na leitura. Diferenças significativas foram detectadas nas taxas de prevalência entre as cidades $(p<0,001) .0$ Transtorno de Déficit de Atenção e Hiperatividade (TDAH) foi o único transtorno mental comórbido com associação significativa com TEA com comprometimento global $(8,2 \% ; p=0,031)$. Transtornos de ansiedade, TDAH e - grupo Qualquer Transtorno Mental foram associados com TEA com comprometimento na aritmética $(13,8 \%$ com $p=0,008 ; 12,4 \%$ com $p<0,001$; $25,6 \%$ com $p<0,001$, respectivamente). Inúmeros correlatos sóciodemográficos (idade $(p=0,018)$, cidade $(p=0,004)$, status sócio-econômico 
$(p=0,007)$, gênero $(p=0,011)$, e $Q I(p<0,001))$ foram associados com Transtorno Específico de Aprendizagem com comprometimento global na amostra.

Conclusões: A validação e normatização de instrumentos que avaliem o desempenho acadêmico é ainda um grande problema em inúmeros países, mas principalmente naqueles de baixa e média renda (PBMR). Como esperado, foi encontrado uma significativa heterogeneidade nas taxas de prevalência de TEA entre as diferentes regiões geográficas do Brasil, sendo esse um país com forte diversidade. TEA com comprometimento global e em aritmética foram significativamente associados com comorbidades psiquiátricas. Todos correlatos avaliados (idade, cidade, status sócioeconômico, gênero, e QI) foram significativamente associados com TEA com comprometimento global.

Descritores: Transtornos de Aprendizagem, Transtornos Mentais, Estudos Transversais, prevalência, criança, adolescente, comorbidade, Manual Diagnóstico e Estatístico de Transtornos Mentais 


\section{Abstract}

Fortes, I. S. Prevalence of specific learning disorders and its association with mental health disorders in children and adolescents from the Epidemiology Study of Mental Health in Brazilian school children - INPD São Paulo: Faculdade de Medicina, Universidade de São Paulo; 2014.

Introduction: Little is known about Specific Learning Disorder (SLD) in Low and Middle Income Countries (LMICs), and even less from representative school samples in small size cities outside huge urban centers. Few studies addressed the new DSM-5 criteria for SLDs. We investigated the prevalence of DSM-5 SLDs, their comorbidities and correlates in school samples of students from the $2^{\text {nd }}$ to $6^{\text {th }}$ grades living in median cities from 4 different geographic regions in Brazil (north, northeast, central and southeast).

Methods: A national test for academic performance (TDE) covering reading, writing and mathematical abilities was applied. Psychiatric diagnoses were assessed by the K-SADS-PL applied to the primary caregiver, and IQ was estimated by WISC-III subtests.

Results: A total of 1,618 children and adolescents were included in the study. The following prevalence rates of SLDs were found: $7.6 \%$ for global impairment, $5.4 \%$ for writing, $6.0 \%$ for arithmetic and $7.5 \%$ for reading impairment. Significant differences were detected in prevalence rates among cities $(p<0.001)$. Attention-deficit/Hyperactivity Disorder (ADHD) was the only comorbidity significantly associated with SLD with global impairment $(8.2 \%$; $\mathrm{p}=0.031)$. Anxiety Disorders, ADHD and the group Any Mental Disorder $(13.8 \%$ with $\mathrm{p}=0.008 ; 12.4 \%$ with $\mathrm{p}<0.001 ; 25.6 \%$ with $\mathrm{p}<0.001$, respectively) were associated with SLD with arithmetic impairment. Several socio-demographic correlates (age $(p=0.018)$, city $(p=0.004)$, socioeconomic status $(p=0.007)$, gender $(p=0.011)$, and $I Q(p<0.001))$ were significantly associated with SLD with global impairment in our sample.

Conclusions: Careful validation and normatization of instruments to assess academic performance is a major problem in LMICs. As expected, we found a significant heterogeneity in prevalence rates of SLD according to geographic 
regions considering that Brazil is a country with a robust diversity. SLD with global and arithmetic impairment were significantly associated with psychiatric comorbidities. All correlates investigated (age, city, socioeconomic status, gender, and IQ) were significantly associated with SLD with global impairment.

Descriptors: Learning Disorders, Mental Disorders, Cross-Sectional studies, prevalence, child, adolescent, comorbidity, Diagnostic and Statistical Manual of Mental Disorders 


\section{Introdução}

\subsection{Visão geral da aprendizagem}

O processo de aprendizagem depende de uma importante tríade: da escola, ambiente através do qual o indivíduo tem acesso à educação; da família, que proporciona oportunidades para o aprendizado; e de aspectos biológicos [39] que estabelecem o grau de aptidão que o indivíduo irá apresentar para absorver o que the é ensinado. Assim, ambos fatores genéticos e ambientais influenciam fortemente no aprendizado. Como exemplo, Haviou-Thomas aponta para a contribuição do componente genético e ambiental para o desenvolvimento das habilidades iniciais linguísticas e da fala e da sua relação com a leitura e a maneira como esta será desenvolvida [21].

Portanto, a partir das primeiras oportunidades de se comunicar, o indivíduo é avaliado pela sociedade que o cerca pelas suas capacidades intelectuais e motoras antes mesmo dele iniciar na escola. Quando a criança entra no final de sua primeira infância, seu sucesso começa também a ser mediado através de seu desempenho escolar, sendo, neste primeiro contato dentro da escola, o momento em que ela demonstra com mais clareza suas aptidões e talentos, assim como suas dificuldades e limitações. A oportunidade de aprendizagem acontece a todo o momento em que a criança se depara com uma nova situação. No ambiente escolar, tanto com a demanda acadêmica quanto na própria socialização com outras crianças e adolescentes, esta oportunidade está presente em inúmeras ocasiões. No entanto, quando há alguma dificuldade no aprender, é importante que professores estejam suficientemente atentos para perceber e intervir, com o propósito de que os obstáculos que impedem o aprendizado sejam removidos. No entanto, quando as dificuldades presentes atrapalham de maneira significativa, é importante que haja o rápido reconhecimento para intervir precocemente, acionando a família do indivíduo e buscando as intervenções necessárias. Quando as dificuldades de aprendizagem se tornam incapacitantes, elas podem se caracterizar como um transtorno de aprendizagem, neste caso tornando mais difícil o tratamento e assim exigindo que o foco de intervenção seja mais específico e intensivo. $O$ 
transtorno de aprendizagem aparece no ambiente escolar com menos frequência do que a dificuldade de aprendizagem, uma vez que esta não possui os critérios diagnósticos necessários para ser considerada transtorno. Inúmeros estudos internacionais apresentam esta diferenciação de gravidade e ocorrência dos quadros através de investigações de prevalência tanto de dificuldade quanto de transtorno de aprendizagem. No entanto, infelizmente ainda evidencia-se grande defasagem e escassez de estudos em países de baixa e média renda (PBMR) como o Brasil, o que dificulta a existência de um quadro real da prevalência de crianças e adolescentes que sofrem de transtorno de aprendizagem, tanto com comprometimento global quanto nas esferas individuais da leitura, escrita, e/ou aritmética.

\subsection{Diferentes conceitos de problemas de aprendizagem}

Os termos transtorno/distúrbio de aprendizagem e dificuldade de aprendizagem não possuem uma definição unânime. Pelo contrário, eles sempre careceram de um consenso internacional para serem reconhecidos, identificados, tipificados e definidos [20].

O Reino Unido, por exemplo, usa o termo learning disability para se referir aos indivíduos com deficiência intelectual [2, 12, 22], assim identificada pela presença de QI igual ou menor que 70 assim como uma habilidade significativamente reduzida para compreender informações novas e complexas, aprender novas habilidades e para ser autosuficiente [5]. Diferentemente do Reino Unido, os Estados Unidos utiliza o mesmo termo learning disability para descrever um conjunto de características manifestadas por dificuldades significativas da aprendizagem [43]. Altarac e Saroha [3] ampliam o significado deste termo para habilidades gerais das quais a aprendizagem depende: "learning disability (LD) é um termo usado para descrever uma constelação de distúrbios manifestados por dificuldades significativas da compreensão, fala, leitura (ambas habilidades de leitura correta e de compreensão do que é lido), escrita, raciocínio, matemática (cálculo e raciocínio matemático), aprendizado de línguas outras do que a língua materna, coordenação, adaptação espacial, memorização, e estudos sociais". Ao mesmo tempo, o Reino Unido se utiliza do 
termo dificuldades específicas da aprendizagem (specific learning difficulties) para se referir às dificuldades ou transtornos de aprendizagem quando os níveis intelectuais ou de inteligência são preservados [22].

\subsubsection{Dificuldade de aprendizagem}

As dificuldades ou problemas de aprendizagem podem ser secundários a ambientes desfavoráveis, principalmente no ambiente da escola e família, por não oferecerem condições adequadas para o desempenho acadêmico positivo das crianças ou adolescentes. Além disso, há a possibilidade de serem decorrentes de problemas emocionais, alterações sensoriais, doenças neurológicas e transtornos mentais como o Transtorno de Déficit de Atenção e Hiperatividade (TDAH). Estima-se, de acordo com estudos em vários países, que as dificuldades de aprendizagem podem variar de 15,0 a $20,0 \%$ no segundo ano escolar (primeira série segundo nomenclatura anterior), mas que esta taxa pode alcançar $50,0 \%$ dos escolares nos primeiros seis anos de escolaridade [39]. Em um estudo na Finlândia, 21,2\% de crianças em idade escolar foram encaminhadas para educação especial em 2001 devido a dificuldades de aprendizagem e em 2004 esta porcentagem aumentou para 28,0\% [58]. Já em um estudo longitudinal com uma amostra de 14,500 estudantes na Austrália em 1994, 36,6\% de crianças do ensino primário e fundamental apresentaram dificuldades de aprendizagem em alguma área no primeiro ano escolar e dois anos depois, em 1996, esta taxa quase se repetiu, caindo apenas 3,3\% para 33,3\% [35]. Nestas taxas de prevalência não foram incluídos os casos que cumpriam com os critérios diagnósticos para transtorno de aprendizagem. Assim, quando um indivíduo apresenta alguma dificuldade no aprender não necessariamente significa que ele tenha transtorno de aprendizagem, pois este último interfere de forma mais aguda e específica no processo de aquisição e manutenção de informações do que a dificuldade de aprendizagem [39]. 


\subsubsection{Transtorno de Aprendizagem}

A definição dos critérios para o diagnóstico do transtorno de aprendizagem é complexa pela dificuldade conceitual existente e sua grande variedade de denominações [30]. A realização do diagnóstico se torna ainda mais difícil devido à possibilidade de haver um problema na aprendizagem da criança ou adolescente mesmo quando este não alcança todos os critérios diagnósticos necessários para identificá-lo como transtorno. Segundo Ohlweiler et al. (2006), a prevalência pode variar entre $2,0 \%$ e $10,0 \%$, de acordo com os diferentes métodos utilizados para se diagnosticar transtorno de aprendizagem que foram relatados em diversos estudos no passado [39].

No entanto, apesar da complexidade da definição dos critérios diagnósticos para os transtornos de aprendizagem devido à dificuldade de interpretar os conceitos existentes e sua ampla variedade de denominações [30], os transtornos de aprendizagem são internacionalmente e basicamente caracterizados por uma inabilidade específica da aprendizagem nas esferas da leitura, escrita, ou matemática, o que contribui para escores significativamente mais baixos do que é esperado para o nível escolar assim como para o nível de desenvolvimento e habilidade intelectual $[4,5]$.

\subsection{Diagnósticos de Transtorno de Aprendizagem na CID-10 e em diferentes versões da DSM:DSM-IV x DSM-5}

\subsubsection{DSM-IV}

De acordo com o DSM-IV, os transtornos de aprendizagem são caracterizados pelos indivíduos apresentarem uma inabilidade específica, como de leitura, escrita ou matemática, o que desencadeia resultados significativamente abaixo do esperado para seu nível de desenvolvimento, escolaridade e capacidade intelectual [4]. A Associação Americana de Psiquiatria, no seu Manual Diagnóstico e Estatístico de Transtornos Mentais [4], apresenta quatro subdivisões para os Transtornos de Aprendizagem: Transtorno da Leitura, Transtorno da Matemática, Transtorno da Expressão 
Escrita e Transtorno da Aprendizagem Sem Outra Especificação enquanto que a Organização Mundial de Saúde, na Classificação Internacional de Doenças [67], denomina os problemas de aprendizagem de transtornos específicos do desenvolvimento das habilidades escolares - F81. Na CID-10, há uma comparação direta entre 0 conceito dos transtornos específicos do desenvolvimento das habilidades escolares e aquele dos transtornos específicos do desenvolvimento da fala e da linguagem - F80 - pela justificativa de ambos apresentarem padrões que saem da curva normal do desenvolvimento que podem ser evidenciados pela dificuldade de aquisição de habilidades desde os primeiros estágios.

Embora seja difícil definir o que represente um funcionamento substancialmente abaixo da média, em geral operacionaliza-se essa definição por uma discrepância de mais de dois desvios-padrão entre rendimento e QI. Uma discrepância menor entre rendimento e QI (isto é, entre 1 e 2 desviospadrão) ocasionalmente é usada, principalmente quando o desempenho de um indivíduo em um teste de Ql é comprometido pela associação de um transtorno no processamento cognitivo, pela comorbidade de um transtorno mental ou condição médica geral que pode estar comprometida, ou mesmo pela bagagem étnica ou cultural do indivíduo [4]. 


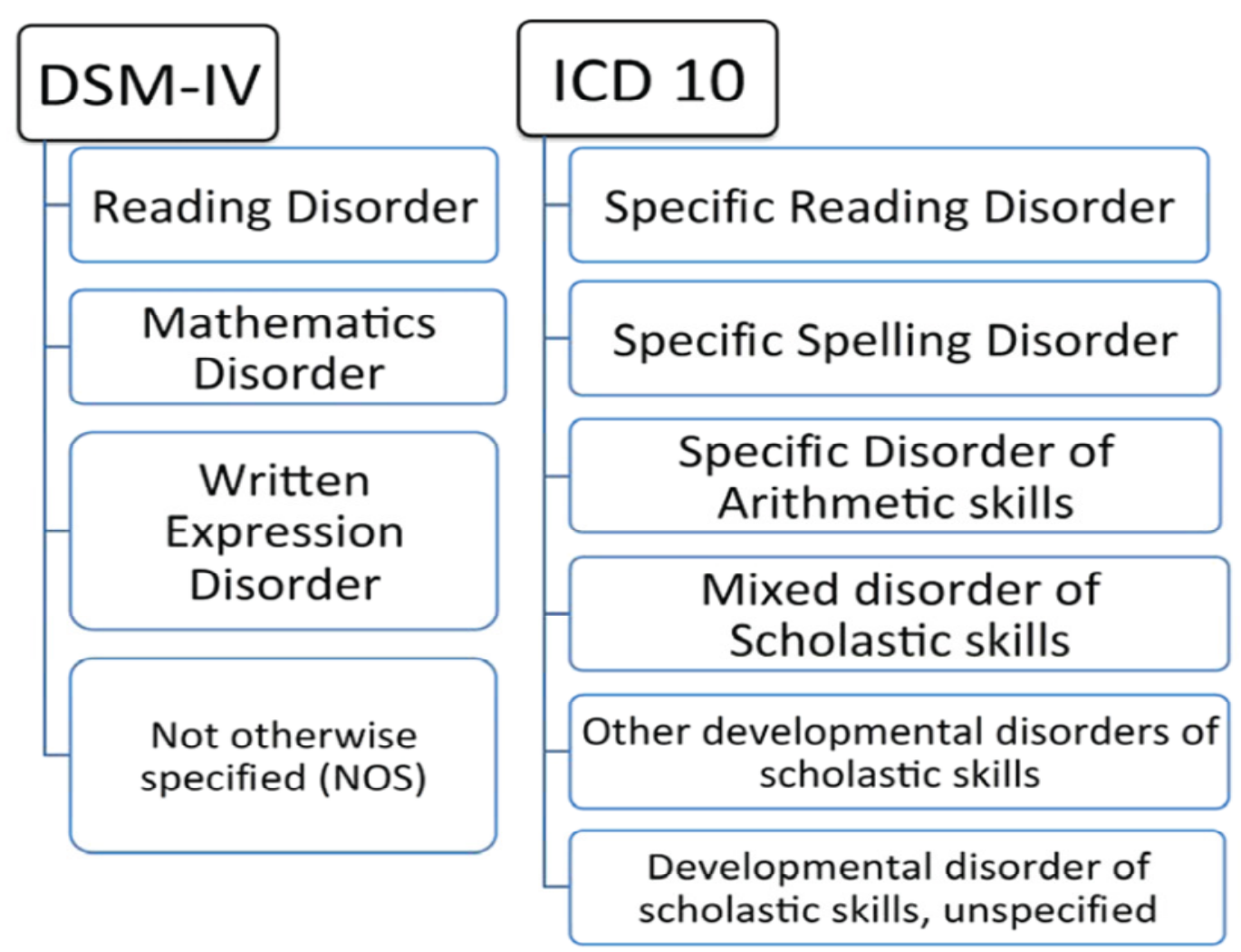

Figura 1. Classificação dos Transtornos de Aprendizagem de acordo com o DSM-IV e CID-10.

Fonte: Tannock, R. Rethinking $A D H D$ and $L D$ in DSM-5: Proposed Changes in Diagnostic Criteria [59].

\subsubsection{DSM-5}

A quinta edição recentemente publicada (maio de 2013) do Manual Diagnóstico e Estatístico dos Transtornos Mentais (DSM-5) [5] realoca o Transtorno de Aprendizagem da seção prévia de "Transtornos primeiramente diagnosticados na Infância ou Adolescência" (Disorders First Diagnosed in Infancy, Childhood, or Adolescence) para uma nova seção denominada de "Transtornos do Neurodesenvolvimento" (Neurodevelopmental Disorders) [59]. Esta nova versão do Manual Diagnóstico e Estatístico dos Transtornos Mentais (DSM) renomeia o Transtorno de Aprendizagem para Transtorno Específico de Aprendizagem (TEA). 
Além disso, inúmeras outras modificações nos critérios diagnósticos do TEA foram implementados. Primeiramente, TEA é agora um diagnóstico único e geral, que incorpora os déficits de desempenho acadêmico, permitindo os médicos a diagnosticarem os indivíduos uma vez que os identificarem como incapazes de obter um desempenho acadêmico em nível de inteligência e idade apropriado [6].

Assim, o DSM-5 [5] descreve as dificuldades e habilidades acadêmicas gerais e fornece especificadores detalhados para as áreas da leitura, matemática, e expressão escrita. A segunda mudança importante do DSM-IV para o DSM-5 foi a eliminação do critério de discrepância de QI e desempenho para TEA. Foi evidenciado que com o critério de discrepância de QI havia uma tendência a identificar em excesso o TEA nos indivíduos com altos escores de QI enquanto que subidentificar TEA entre aqueles com baixos escores de QI, mesmo sendo ainda um QI acima de 70 [19]. Entretanto, a deficiência intelectual ainda segue um critério de exclusão também no DSM-5. A terceira mudança é uma exigência de que as dificuldades de aprendizagem sejam persistentes por um período de pelo menos 6 meses e que determinem uma performance acadêmica abaixo do esperado para padrões de idade e ano escolar, mesmo diante da implementação de intervenção baseada em evidências [59]. Este critério diagnóstico tem como objetivo assegurar que o baixo desempenho não seja resultado de ensino inadequado na sala de aula e assim, uma abordagem baseada em resposta à intervenção (RTI) deve acontecer antes de uma avaliação para TEA [20], apesar de ser importante considerar que nem todas intervenções são oferecidas em maneira padronizada. Portanto, o diagnóstico feito baseado em critério de RTI pode ser difícil já que o treinamento de professores em intervenção baseada em evidências é quase inexistente [20]. Um aspecto importante do TEA no DSM-5 é que apesar de geralmente estar aparente nos primeiros anos escolares, alguns indivíduos podem somente demonstrar grandes dificuldades de aprendizagem mais tarde, permitindo que o diagnóstico seja feito a qualquer momento a partir do início do ensino formal, na adolescência, e até na idade adulta [5]. 
Disorders First Diagnosed in Infancy,

Childhood, or Adolescence

Transtorno da leitura (dislexia)

Transtorno da matemática (discalculia)

Transtorno da expressão da escrita

(disgrafia)

Transtorno de aprendizagem Não-

Especificado

Discrepância de QI

Eliminação do critério de discrepânca de QI

Ponto de corte de pelo menos 1,5 desviospadrão abaixo da média da população por idade

Diagnóstico pode ser feito a qualquer momento a partir do início do ensino formal

\subsection{Transtorno Específico de aprendizagem}

A etiologia do transtorno específico de aprendizagem ainda não é definida, mas acredita-se que por ser parcial ou totalmente irreversível, há o provável envolvimento de fatores biológicos, que podem surgir já como alguma alteração no desenvolvimento cerebral do feto. Há a suposição de que o surgimento do transtorno de aprendizagem se relacione a distúrbios de interligação de informações em várias regiões do cérebro [39].

Transtorno Específico de Aprendizagem (TEA) é definido como falha em cumprir, de acordo com o nível de ano escolar, com padrões apropriados de expressão e compreensão oral, expressão da escrita, habilidades de leitura básica e de fluência de leitura, compreensão de texto, e habilidades de realizar 
cálculos matemáticos e/ou resolução de problemas, apesar de oportunidades de aprendizagem e ensino condizentes com a idade [59].

Revisitando a literatura sobre o TEA, é surpreendente a variedade de métodos para diagnosticar este transtorno em estudos internacionais antigos e atuais [16], o que resulta na ausência de consistência terminológica e causa impacto nos critérios diagnósticos, assim como no diagnóstico e tratamento [59]. Existe uma grande lacuna de uma média de 3,5 anos entre a primeira suspeita da mãe sobre o problema e a idade em que a criança é diagnosticada [3].

O diagnóstico de TEA é feito a partir da análise clínica do histórico médico, educacional, familiar, e de desenvolvimento do indivíduo, assim como deve ser baseado em escores de testes e observações dos professores e na resposta da criança/adolescente diante de intervenções acadêmicas [5]. Além disso, habilidades acadêmicas atuais precisam estar bem abaixo da média dos escores esperados considerando a idade cronológica do indivíduo (pelo menos 1,5 desvio-padrão (DP) abaixo da média da população por idade [5]), a inteligência medida, e a educação adequada para a idade avaliada por testes culturalmente e linguisticamente apropriados nas esferas da leitura, escrita, e/ou matemática $[5,6,59]$. Assim, leitura incorreta ou com muito esforço, pobre expressão da escrita, dificuldades em recordar fatos numerais, ou raciocínio matemático incorreto fazem parte dos sintomas de TEA. Para complementar, os déficits precisam ser persistentes e não melhor explicados por distúrbios do desenvolvimento, neurológicos, sensoriais (visão ou audição), e motores, nem por déficit intelectual (ex., o escore de coeficiente intelectual (QI) precisa ser maior do que 70 [5]), e precisam interferir significativamente no desempenho acadêmico e ocupacional, ou atividades diárias [6]. O tratamento de TEA tem ênfase em intervenções educacionais [3].

\subsubsection{Impacto na sociedade}

O diagnóstico do transtorno específico de aprendizagem é geralmente feito quando a criança se encontra na escola, pois este não se torna evidente até o momento em que exista demanda de trabalho acadêmico. Entretanto, 
crianças que aos cinco anos de idade apresentam problemas de comportamento relacionados com atrasos no desenvolvimento da fala/linguagem já devem ser identificadas pois são um grupo de risco importante para o surgimento de TEA mais para frente [60].

A partir do momento em que a exigência acadêmica aumenta, a partir da alfabetização, e a criança se depara com grande dificuldade em aprender certa habilidade, como a leitura, por exemplo, muitas vezes perde a motivação em ir para a escola, o que pode levar a inúmeras faltas consecutivas até o momento em que deixa de ir por completo (dropout), o que pode ser visto em $40,0 \%$ dos casos [4]. Esta taxa altíssima de evasão escolar em crianças e adolescentes com TEA é reflexo do impacto que a falta tanto de diagnóstico precoce quanto de possibilidade de tratamento adequado causa. Assim, a falta de identificação das dificuldades de aprendizagem persistentes podem contribuir fortemente para grande desgaste emocional, tanto para os indivíduos afetados quanto para suas famílias. Por estes motivos, é evidente que o impacto do TEA na vida daqueles afetados e suas famílias pode ser imenso [60]. Problemas sociais, comportamentais e de auto-estima na escola são frequentemente relacionados ao pobre desempenho acadêmico e podem ser causa de desajustes emocionais ainda maiores [1, 59, 66]. Inúmeros achados sugerem que esses efeitos podem impactar a vida adulta e levar a dificuldades significativas de obtenção e permanência em empregos assim como desajustes sociais [4, 5, 31]. Portanto, a identificação e intervenção precoce são de extrema importância para evitar esses tipos de problemas, que tendem a somente piorar no decorrer do tempo, uma vez não diagnosticados e/ou tratados $[6,31,66]$. Apesar do transtorno de aprendizagem não ter cura, as condições e sintomas que fazem parte do quadro podem ser tratados para que as crianças possam se adaptar, conquistar sucesso acadêmico, e viver vidas produtivas e compensadoras [3].

\subsubsection{Estudos de prevalência}

As taxas de prevalência para TEA se diferenciam significativamente entre as investigações, como evidenciado por Al-Yagon et al. [2], que relatam 
prevalências muito diversas entre diferentes países, variando de uma baixa taxa de 1,2\% em um estudo epidemiológico grego feito em 2004 e 1,6\% quando repetido em 2005, para uma altíssima taxa de 20,0\% em um estudo na Austrália. Já Ohlweiler et al. (2006) relatam uma faixa de prevalência entre $2,0 \%$ a 10,0\%, que varia devido aos diferentes métodos diagnósticos nos diversos estudos [39]. A National Survey of Children's Health (NSCH) do ano de 2003 nos Estados Unidos encontrou uma estimativa de prevalência ao longo da vida de $9,7 \%$ de transtorno de aprendizagem em crianças/adolescentes de 3 a 17 anos de idade e dependendo do número de critérios de definição, de 1 a 5, a prevalência de transtornos de aprendizagem variou de 15,0 a 87,8\% [3]. Enquanto isso, Taanila et al. [58] relatam um aumento com o passar do tempo na porcentagem de crianças em idade escolar que foram encaminhadas para educação especial na Finlândia pelo diagnóstico de transtorno de aprendizagem: 21,2\% em 2001 e 28,0\% no ano de 2004.

Enfatizando os especificadores das esferas de aprendizagem, assim como são chamados no novo manual diagnóstico DSM-5 [5], inúmeros estudos internacionais relatam diferentes taxas de prevalência. Para comprometimento na leitura (colocado como dislexia devido à antiga denominação do DSM-IV [4]), Huc-Chabrolle et al. (2010) relatam taxas em estudo na França em torno de $5,0 \%$ a $10,0 \%$ em crianças de idade escolar [23], mesma variação de prevalência colocada por Shastry [52]. De acordo com o Parliamentary Office of Science and Technology no Reino Unido [41], a prevalência de TEA na esfera da leitura aparece mais alta em pessoas cuja primeira língua é a inglesa do que em indivíduos que tenham outra língua materna, com a hipótese de que o inglês tenha mais diferenças na maneira em que uma letra pode ser pronunciada do que a maioria das outras línguas, assim como mais inconsistências no jeito em que as palavras são lidas e escritas.Huc- Chabrolle et al. [23] (2010) também relatam uma taxa de comorbidade de TEA com comprometimento na matemática (previamente denominado de discalculia no DSM-IV [4]) e TEA com comprometimento na leitura de 25,0\%. Além disso, os comprometimentos nas áreas de aprendizagem da leitura, escrita, e aritmética no TEA tendem a ocorrer concomitantemente [30]. No DSM-5 é colocado que entre $5,0 \%$ e $15,0 \%$ das crianças em idade escolar tenham TEA com 
comprometimento nas três esferas de aprendizagem da leitura, escrita, e matemática [5].

\subsection{Comorbidades}

Os transtornos de aprendizagem podem acontecer sozinhos ou acompanhados de inúmeras complicações, incluindo os transtornos mentais da infância e adolescência em geral, como o TDAH [43] e Transtornos de Ansiedade, que estão freqüentemente associados com um pobre desempenho escolar e, conseqüentemente, com problemas de aprendizagem.

Os transtornos de aprendizagem por si só já interferem significativamente no rendimento escolar ou nas atividades da vida diária que exigem habilidades de leitura, matemática ou escrita e a associação de qualquer outro transtorno prejudica ainda mais este quadro. A comorbidade dos transtornos de aprendizagem com transtornos mentais é comum mesmo que não haja uma relação causal entre as condições. A associação, que pode variar entre leve e grave, entre os transtornos de aprendizagem e problemas emocionais e comportamentais é descrita em inúmeros estudos [58], assim como a forte comorbidade entre TDAH e transtorno de aprendizagem [9].

Crianças com TDAH sem transtorno de aprendizagem apresentam algum grau de dificuldade de aprendizagem, assim como aquelas com transtorno de aprendizagem sem TDAH tem problemas de desatenção em algum nível [32]. Dessa forma, sugere-se através dos resultados dessa forte associação em inúmeros estudos, que problemas de desatenção e de aprendizagem estão correlacionados e tem a tendência de coexistirem. $O$ TDAH é o diagnóstico psiquiátrico mais comumente associado com transtorno de aprendizagem com comprometimento na leitura [23].

De acordo com o estudo de 2007 de estimativa de prevalência de transtorno de aprendizagem ao longo da vida em crianças nos Estados Unidos [3], houve um grande aumento na prevalência de transtorno de aprendizagem em crianças com demanda de necessidades especiais de saúde ou que estão usando serviços variados em saúde. Assim, Altarac e Saroha [3] concluem que transtorno de aprendizagem é uma comorbidade importante neste grupo de 
crianças e que crianças com transtorno de aprendizagem no geral apresentam grandes chances de terem outras dificuldades ou transtornos mentais. De acordo com o Maternal and Child Health Bureau (MCHB), dos Estados Unidos, as crianças com necessidades especiais de saúde (CSHCN) são aquelas que tem risco de desenvolver ou que já tem alguma condição crônica emocional, comportamental, de desenvolvimento, ou física e que assim precisam de mais serviços de saúde ou relacionados do que crianças sem essas condições [3].

\subsubsection{Estudos de prevalência}

Taxas de prevalência do transtorno de aprendizagem na população com TDAH variam na literatura de 17,0 a 70,0\%, dependendo das definições e critérios utilizados [18]. Considerando o estudo com a taxa mais alta de 70,0\% [32], os indivíduos com a comorbidade apresentam problemas mais graves de aprendizagem do que aquelas sem o TDAH e possuem também maiores problemas de desatenção do que crianças com TDAH sem o transtorno de aprendizagem. De acordo com Huc-Chabrolle et al., entre 15,0 e $40,0 \%$ dos indivíduos com transtorno de aprendizagem com comprometimento na leitura cumprem com os critérios diagnósticos de TDAH e 25,0 a 40,0\% das crianças diagnosticadas com TDAH também são disléxicas [23].

\subsection{Justificativa}

O Estudo Epidemiológico de Saúde Mental do Escolar Brasileiro do INPD (Instituto Nacional de Psiquiatria do Desenvolvimento) é o primeiro a investigar a prevalência dos transtornos mentais da infância e adolescência assim como os problemas de aprendizagem em quatro regiões do Brasil: norte, nordeste, centro-oeste e sudeste.

De acordo com o Manual Diagnóstico e Estatístico dos transtornos mentais, $4^{\text {a }}$ edição [4], $10,0 \%$ a $25,0 \%$ de indivíduos com transtorno da conduta, transtorno opositivo-desafiador, transtorno de déficit de atenção e hiperatividade, transtorno depressivo maior ou transtorno distímico apresentam transtorno de aprendizagem. Essa prevalência pode ser ainda maior, assim 
como a quantidade de transtornos associados principalmente quando esta associação é com dificuldades de aprendizagem não caracterizadas como transtorno, por serem um conceito mais abrangente [64]. Os transtornos e dificuldades de aprendizagem também apresentam associação freqüente com diferentes comorbidades como problemas no desenvolvimento motor. A literatura indica que pelo menos $50,0 \%$ de estudantes com problemas de aprendizagem apresentam um distúrbio no desenvolvimento da coordenação motora [13]. Desse modo, estudos atuais de prevalência são extremamente necessários para que se possa traçar um perfil mais real dos problemas que as crianças e adolescentes enfrentam diante da presença de transtorno de aprendizagem. Além disso, a presença da comorbidade entre transtorno de aprendizagem e transtornos mentais implica em maiores prejuízos para o indivíduo acometido e maior carga para a família. Existem evidências de que o transtorno de aprendizagem se torna mais persistente quando há a associação com problemas comportamentais nos primeiros anos escolares em comparação à ausência de qualquer comorbidade [48].

Com isso, o presente estudo procura preencher a lacuna existente devido à falta de investigações que visam avaliar a prevalência do TEA e suas comorbidades em países em desenvolvimento, especialmente usando os novos conceitos do DSM-5. Os poucos estudos já feitos nos países de baixa e média renda valeram-se ou de amostras clínicas ou de amostras escolares não-representativas de imensas áreas urbanas [2] ou somente estimaram o número de crianças e adolescentes com TEA [57]. Assim, como evidencia-se na tabela 6 , do anexo $A$, as escolas municipais são a grande maioria no Brasil, sendo responsáveis por aproximadamente $67 \%$ do ensino no país. Dessa forma, o estudo teve como foco os estudantes das escolas públicas municipais a fim de englobar o máximo possível o quadro de prevalência do transtorno de aprendizagem e suas comorbidades de acordo com a realidade brasileira. 


\section{Objetivos}

1) Investigar a prevalência de TEA tanto com comprometimento global quanto com comprometimento nas esferas da leitura, aritmética, e escrita, de acordo com os critérios do DSM-5, em cidades de pequeno porte em quatro diferentes regiões geográficas do país (norte, nordeste, centro-oeste, e sudeste).

2) Avaliar a freqüência da associação entre transtornos mentais da infância e da adolescência com transtornos de aprendizagem nestas quatro regiões diferentes. Nesse sentido, buscou-se determinar quais transtornos mentais se associam com as esferas da aprendizagem da leitura, aritmética e escrita, assim como com o comprometimento global da aprendizagem.

3) Estudar o papel dos correlatos demográficos, cognitivos e sócioeconômicos (cidade; QI estimado; idade; gênero e status sócioeconômico) na prevalência de TEA. 


\section{Hipóteses}

1) A prevalência de TEA em amostras de escolares brasileiros de quatro cidades de regiões diversas do país será similar àquela encontrada em outros países, principalmente às prevalências dos países de baixa e média renda.

2) A prevalência dos transtornos psiquiátricos comórbidos ao TEA será similar a de outros países, principalmente às dos países de baixa $e$ média renda.

3) Em relação aos correlatos demográficos, cognitivos e sócioeconômicos, haverá uma grande heterogeneidade nas taxas de prevalência de transtorno específico de aprendizagem entre as diferentes cidades em regiões geográficas distintas. Menos QI e menor nível de sócio-econômico e maior idade se associarão significativamente à maior prevalência de TEA. 


\section{Métodos}

\subsection{Antecedentes - Estudo principal}

O estudo que originou o presente projeto foi um de dezesseis projetos do INPD - Instituto Nacional de Psiquiatria do Desenvolvimento: O Estudo Epidemiológico do Escolar Brasileiro que visou mapear os transtornos mentais e de aprendizagem em regiões diferentes no Brasil, assim como os fatores de risco e proteção para estes transtornos.

\subsection{Aspectos Éticos}

O Estudo Epidemiológico de Saúde Mental do Escolar Brasileiro, do qual o presente projeto está inserido, foi aprovado pelo Comitê de Ética da Universidade de São Paulo, assim como obteve aprovação das Secretarias de Educação dos estados onde a pesquisa foi conduzida. Consentimento informado foi solicitado e assinado por todas as mães/responsáveis das crianças e adolescentes que participaram das entrevistas. As crianças e adolescentes sorteados para o estudo também forneceram aprovação verbal para participarem. Outro passo importante foi tomado para que houvesse a sistematização de encaminhamento dos casos detectados para os serviços de saúde da região. Os entrevistadores, psicólogos do estudo, foram orientados a dar especial atenção e identificação dos casos mais graves com necessidade de urgência de encaminhamento e intervenção, como suspeita de risco de suicídio da mãe ou criança. Assim, as Secretarias de Saúde de todas as quatro cidades (Itaitinga, Goianira, Caeté, e Rio Preto da Eva) foram contactadas para que o processo de encaminhamento fosse facilitado. As Secretarias de Educação foram importantes pontes para que os responsáveis das Secretarias de Saúde recebessem os encaminhamentos com o conhecimento do estudo realizado. 


\subsection{Desenho do estudo}

O Estudo Epidemiológico sobre a Saúde Mental do Escolar Brasileiro (INPD - Instituto Nacional de Psiquiatria do Desenvolvimento) é um estudo transversal de associação que avaliou dados sobre transtornos psiquiátricos, problemas de saúde e de aprendizagem de 2.000 estudantes, sendo a amostra total de 500 crianças e adolescentes em cada cidade de uma das quatro regiões geográficas brasileiras envolvidas: norte, nordeste, centro-oeste e sudeste. Deste estudo multicêntrico originou-se a pesquisa aqui apresentada, cujo foco de investigação foram os transtornos específicos de aprendizagem (TEA) da população do estudo maior previamente citado.

Este estudo descritivo transversal foi conduzido nas cidades de: Rio Preto da Eva (estado = Amazonas; região geográfica $=$ norte; população $=$ 25.719; IDH = 0,611); Itaitinga (estado = Ceará; região geográfica = nordeste; população = 35.817; IDH = 0,626); Goianira (estado = Goiás; região geográfica = centro-oeste; população = 34.060; IDH = 0,694); and Caeté (estado = Minas Gerais; região geográfica $=$ sudeste; população $=40.750 ; \mathrm{IDH}=0,728)$ [8]. Esses dados foram coletados a partir do último censo nacional, realizado em 2010. A população do Brasil em 2010 era de 190.732 .694 e seu IDH era de 0,727 .

Desde 2001, é mandatório a matrícula em instituição educacional para todas as crianças e adolescentes brasileiros a partir de seus 6 anos de idade e o vínculo escolar precisa ser mantido até o final do ensino fundamental (9 anos no total) [44]. A maioria dos estudantes brasileiros freqüenta escolas públicas, como é o caso nas cidades participantes do estudo. As escolas públicas nestes locais representam o seguinte percentual do total de escolas: $90 \%$ em Caeté (sudeste); 96\% em Goianira (centro-oeste); 93\% em Itaitinga (nordeste); e 95\% em Rio Preto da Eva (norte) [24].

Bancos de dados locais de estudantes matriculados permitem a identificação precisa de todos alunos de escolas públicas de qualquer município brasileiro. Em cada site, a Secretaria Municipal de Educação providenciou para o presente estudo uma única lista de todas as crianças e adolescentes matriculados em escolas públicas do segundo ao sexto ano 
escolar. O cálculo amostral foi elaborado considerando uma população total de estudantes do segundo ao sexto ano do ensino fundamental nas quatro cidades igual à cerca de 10.000 individuos (população total), uma prevalência de TEA ao redor de $10 \%$, erro alfa de $5 \%$ e poder de $95 \%$. A partir dessa estimativa, a amostra deveria ser composta de 1.360 estudantes. Considerando possíveis perdas, selecionamos randomicamente 500 estudantes em cada cidade da pesquisa, totalizando 2.000 estudantes. Nenhuma escola se recusou a participar. A ano escolar inicial selecionado foi o segundo ano para assegurar que todas as crianças já tivessem passado pela alfabetização, ou seja, pelo primeiro ano escolar, permitindo que já fosse possível que elas demonstrassem as habilidades de leitura, escrita, e matemática condizentes aos ensinamentos que the foram passados. Estas capacidades eram necessárias para a avaliação da presença ou ausência do transtorno específico de aprendizagem.

Três tentativas foram feitas por telefone na busca de contactar com sucesso a mãe, preferencialmente, ou na ausência desta, outro cuidador que pudesse ser considerado equivalente à mãe como cuidador principal (ex.: pai ou avó/avô, preferencialmente. Na ausência destes, o irmão/irmã mais velhos e de maior idade poderiam ser considerados também, assim como tios). Todos procedimentos de pesquisa foram cuidadosamente e verbalmente explicados através da ligação onde consentimento verbal foi requerido à mãe ou ao outro principal cuidador em questão, permitindo a criança ou adolescente a participar do estudo. Na mesma ligação, a data e hora de uma entrevista presencial foram agendadas. Se o cuidador e a criança não aparecessem para o primeiro agendamento, outras duas tentativas no mínimo eram feitas almejando concluir com sucesso todos os processos da entrevista tanto com a criança/adolescente quanto com à mãe/outro cuidador principal. Os seguintes instrumentos foram aplicados à criança ou adolescente: os subtestes cubos e vocabulário da Escala de Inteligência Wechsler para Crianças - Terceira Edição (WISC-III) [65]; e o Teste de Desempenho Escolar (TDE) [56]. Enquanto a criança estava realizando os testes acima mencionados, o/a psicólogo/a responsável pela entrevista do cuidador correspondente the aplicava a entrevista K-SADS-PL (Schedule for Affective Disorders and Schizophrenia for School-Age Children- 
Present and Lifetime Version) [26], assim como o questionário sócio-econômico e de fatores de risco e proteção.

Como é demonstrado na Figura 2, a cidade de Caeté tinha originalmente 2.141 nomes na lista, Goianira tinha 2.910 nomes; Itaitinga apresentava 2.950 nomes enquanto que a quarta e última cidade, Rio Preto da Eva, tinha 2.171 nomes. Das 2.000 crianças e adolescentes aleatoriamente sorteados/selecionados para o estudo, somente 11 famílias recusaram-se a participar, enquanto que 126 famílias apesar de aceitarem a inclusão na pesquisa, não apareceram para nenhuma das três entrevistas agendadas. Além disso, não foi possível encontrar ou contactar com sucesso 128 famílias. Apesar do critério de inclusão que enfatiza a necessidade das crianças e adolescentes sorteados estarem propriamente matriculados em ensino regular do segundo ao sexto ano, 15 indivíduos tiveram que ser excluídos da amostra por não confirmarem esta elegibilidade, sendo que 13 estavam matriculados em turmas que não podem ser consideradas como parte do ensino regular; e 2 estavam institucionalizados em casa de detenção para menores infratores e com isso não tinham um responsável ou cuidador principal que pudesse comparecer à entrevista e realizar o K-SADS-PL, nem o questionário sócioeconômico e de fatores de risco e proteção. O número final de crianças e adolescentes que foram considerados sujeitos elegíveis para este estudo foi de 1.720, o que indica uma perda amostral de 14,0\%. Entretanto, após a realização do teste de QI estimado com as crianças e adolescentes, através dos subtestes cubos e vocabulário do WISC-III, foi necessária a exclusão daqueles que obtiveram um IQ igual ou abaixo de 70 , a fim de que fosse possível a investigação do transtorno específico de aprendizagem. Assim, 102 indivíduos foram excluídos da amostra, o que resultou em uma amostra de 1.618 indivíduos que efetivamente participaram de todas as análises do estudo. 
Figura 2 - Amostra, Recrutamento e Seleção

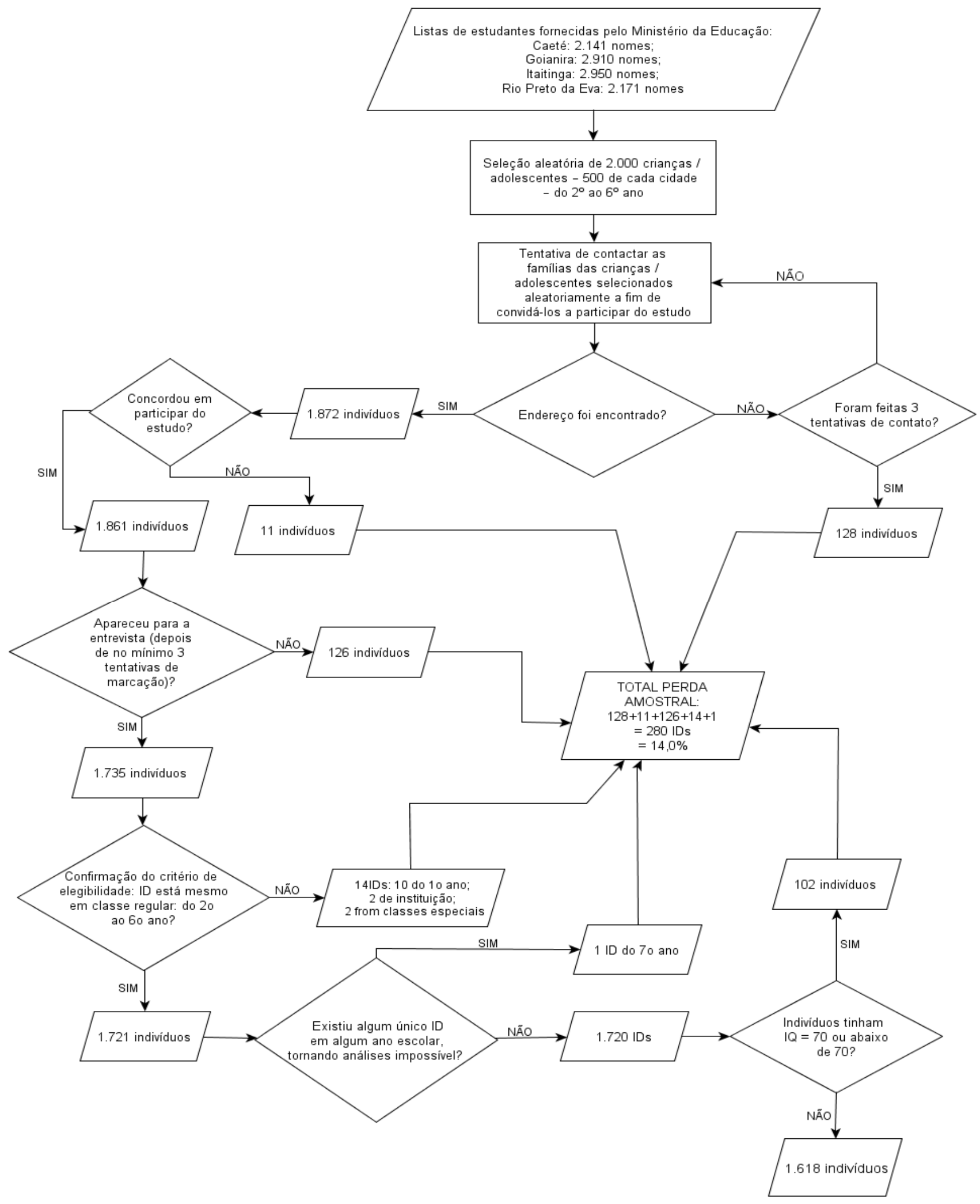




\subsection{Amostra}

\subsubsection{Critérios de Inclusão}

Para que as crianças e adolescentes participassem do estudo precisavam primeiramente residir em uma das quatro cidades escolhidas por conveniência para a pesquisa de campo do nosso estudo, sendo elas: Itaitinga (nordeste), Caeté (sudeste), Goianira (centro-oeste), ou Rio Preto da Eva (norte). Os critérios de seleção desses quatro sites foram: (1) estar geograficamente próximo da capital do estado onde se encontra; (2) ter um Índice de Desenvolvimento Humano (IDH) similar à media brasileira; e (3) ter aproximadamente 30.000 habitantes, já que $84,7 \%$ dos municípios brasileiros tem menos que 50.000 habitantes [25]. As crianças e adolescentes tinham que estar incluídas nas listas fornecidas pelas Secretarias de Educação de cada município, confirmando o critério de elegibilidade de estarem efetivamente matriculadas em ensino regular da rede pública. Uma vez presentes nas listas correspondentes às cidades onde residiam, somente os indivíduos matriculados do segundo ao sexto ano escolar poderiam ser aleatoriamente sorteados da amostra total de todas as escolas públicas da cidade em questão.

\subsubsection{Critérios de Exclusão}

Crianças e adolescentes com QI igual ou abaixo de 70 foram excluídos da amostra por apresentarem déficit intelectual e com isso não preencherem o critério de elegibilidade para permitir a segunda etapa da pesquisa, ou seja, a avaliação da presença ou não do transtorno específico de aprendizagem.

\subsection{Instrumentos de avaliação e treinamento}

Após dois anos e meio de elaboração do desenho da pesquisa e do término do estudo de campo nas quatro cidades, dados foram levantados sobre a prevalência dos transtornos mentais da infância e adolescência diagnosticados com o instrumento diagnóstico K-SADS-PL [26], assim como 
dados de prevalência para a investigação do transtorno específico de aprendizagem foram buscados nessa população utilizando o Teste de Desempenho Escolar (TDE) [56], juntamente com os fatores de risco e proteção envolvidos. $O$ status sócio-econômico foi investigado pelo Questionário sócio-econômico e de fatores de risco e proteção.

\subsubsection{TDE}

O TDE é um instrumento psicométrico que busca oferecer de forma objetiva uma avaliação das capacidades fundamentais para o desempenho escolar, mais especificamente da escrita, aritmética e leitura, indicando de uma maneira abrangente quais são as áreas da aprendizagem escolar que estão preservadas ou prejudicadas na criança [56]. A padronização do TDE foi realizada a partir de uma amostra estratificada de igual proporção, de 538 escolares da $1^{\text {a }}$ a $6^{\underline{a}}$ série do antigo sistema educacional (referentes ao $2^{\circ}$ ao $7^{\circ}$ ano da atual nomenclatura) do Ensino Fundamental. Havia uma média de 90 estudantes em cada série/ano distribuídos em seis escolas de Porto Alegre, Rio Grande do Sul, sendo duas municipais, duas estaduais e duas particulares. Em cada escola foram selecionados aleatoriamente 15 alunos de cada série/ano. A derivação dos dados de normatização foi realizada a partir da média dos Escores Brutos (EB) e Desvio Padrão (DP), calculados para cada um dos estratos da amostra por série/ano e para idade cronológica. A classificação por série foi dividida em três grupos: Inferior, Médio e Superior. Para cada subteste, Escrita, Aritmética e Leitura, foram desenvolvidos diferentes processos de construção e validação. Foi realizada também análise de consistência interna para um dos subtestes, incluíndo o coeficiente de correlação item-total e o coeficiente alfa, que é a estimativa do coeficiente de fidedignidade no subteste [56].

\subsubsection{K-SADS-PL}

Já o K-SADS-PL é uma entrevista diagnóstica semi-estruturada utilizada para acessar a presença de psicopatologia atual e passada em crianças e 
adolescentes, sendo reconhecida e utilizada mundialmente [26, 27]. Foi baseada nos critérios da terceira edição revisada (DSM-III-R) e da quarta edição (DSM-IV) do Manual Diagnóstico e Estatístico dos Transtornos Mentais (Diagnostic and Statistical Manual of Mental Disorders) [4]. A versão brasileira do K-SADS-PL apresenta equivalência de conteúdo em relação ao instrumento original e excelentes propriedades psicométricas, indicando que esta versão é apropriada para ser aplicada na prática clínica e em pesquisa na área de saúde mental da infância e adolescência. A validade de conteúdo foi avaliada comparando-se a retrotradução da versão brasileira com o instrumento original. A validade de constructo foi avaliada: (1) comparando-se a freqüência de transtornos detectados pela K-SADS-PL com dados de prevalência encontrados na literatura, (2) comparando-se os padrões de comorbidade baseados na K-SADS-PL com os referidos na literatura, (3) examinando-se a validade convergente da K-SADS-PL em relação ao Child Behavior ChecklistCBCL ( $N=78)$, e (4) verificando-se a existência de associação entre transtornos mentais nas crianças, identificados pela K-SADS-PL, e problemas de saúde mental nas mães, identificados pelo Self-Report Questionnaire (SRQ-20). O estudo da confiabilidade entre-avaliadores foi baseado na pontuação da KSADS-PL obtida por duas psiquiatras da infância, uma aplicando a seção de rastreamento e a outra observando $(\mathrm{N}=30)$. O estudo da confiabilidade testereteste foi baseado na pontuação da seção de rastreamento obtida pela mesma psiquiatra da infância em duas ocasiões, com intervalo de tempo de uma a oito semanas $(\mathrm{N}=16)$ [10].

\subsubsection{WISC-III}

A Escala de Inteligência Wechsler para Crianças - $3^{\text {a }}$ edição (WISC-III) tem como objetivo avaliar a capacidade intelectual de crianças [65]. O WISC-III é composto por 13 subtestes, organizados em dois grupos: Verbais e Perceptivos-motores ou de Execução. Os Subtestes Verbais são compostos pelos ítens: Informação, Semelhanças, Aritmética, Vocabulário, Compreensão e Dígitos, enquanto que os subtestes de Execução são formados pelos ítens: Completar Figuras, Código, Arranjo de Figuras, Cubos, Armar Objetos, 
Procurar Símbolos e Labirintos. No entanto, somente os subtestes vocabulário e cubos foram utilizados nesse estudo, para a avaliação do QI estimado como triagem para déficit intelectual.

A pesquisa para a padronização brasileira do instrumento foi realizada com 801 crianças e adolescentes com idade entre 6 anos e 16 anos e 11 meses da cidade de Pelotas (Rio Grande do Sul), sendo a proporção semelhante de meninos $(49 \%)$ e meninas $(51 \%)$. Além disso, trinte e quatro instituições fizeram parte da investigação, sendo elas localizadas no centro e periferia [65].

\subsubsection{Questionário Sócio-econômico e de Fatores de Risco e} Proteção

Status sócio-econômico da família foi avaliado por um questionário desenvolvido pela $A B E P$ que tem como objetivo categorizar a população de acordo com o poder de consumo da família [7]. O instrumento é um dos mais usados no Brasil e leva em consideração principalmente o número de eletrodomésticos e o nível de educação do chefe da casa.

\subsection{Variáveis estudadas}

\subsubsection{Diagnósticos Psiquiátricos}

Os diagnósticos psiquiátricos foram avaliados por grupos de entrevistadores formados por psicólogos treinados na aplicação do instrumento denominado KSADS-PL [26, 27]. A triagem de autismo não consta na parte principal de rastreamento do K-SADS-PL, constando apenas na seção de suplementos, e por isso foi retirada da versão epidemiológica do instrumento, 0 K-SADS-E [37].

Dois psicólogos previamente treinados foram responsáveis pelo treinamento de cada time de entrevistadores nas quatro cidades do estudo, assim como foram também os responsáveis pela supervisão local e por Skype, 
uma vez que as entrevistas em campo foram iniciadas. O treinamento para este instrumento teve tempo total de 15 horas incluindo teoria e prática.

\subsubsection{Transtorno Específico de Aprendizagem}

Problemas nas capacidades fundamentais para um bom desempenho escolar foram avaliados através da performance das crianças e adolescentes nos subtestes de Leitura, Aritmética e Matemática do TDE, que podem ser fortes indicadores de dificuldades de aprendizagem, sendo portanto um importante teste de triagem (screening) para detectar as áreas de fraquezas e/ou potencialidades do examinando, necessário na avaliação da possível presença de um transtorno de aprendizagem. O DSM-5 propõe um ponto de corte de 1,5 DP abaixo da média esperada por idade para diagnosticar TEA [5]. Uma vez que a normatização do TDE é baseada em uma amostra de apenas um estado [56], decidimos apresentar três taxas de prevalência: a) uma que reflete os escores abaixo de 1,5 da média calculada para cada ano escolar da amostra; b) a segunda que utiliza o escore bruto de cada indivíduo da amostra e a média e DP apresentados nas tabelas normativas do TDE para seu ano escolar a fim de comparar com a taxa de prevalência onde se utilizou a média e DP da própria amostra, previamente citada; c) a terceira que exige que um desempenho nas três esferas da escrita, leitura e aritmética ou em cada uma individualmente esteja 2 DP abaixo do desempenho em QI do indivíduo em relação à amostra do estudo, a fim de também comparar com a taxa de prevalência onde se usou 1,5 DP (por exemplo, se um indivíduo tem o escore de QI 1 DP abaixo da média e os escores de leitura, matemática e escrita, todos 1,7 DP abaixo da média, ele não tem TEA por essa definição, já que a diferença é de 0,7 DP e não 2 DP). Alunos com escores abaixo de 1,5 DP de acordo com essas normas foram considerados como tendo TEA. Essas análises tiveram o propósito de documentar que as normas derivadas com base em um só estado são claramente inadequadas para representar toda a população em um país tão diverso como o Brasil.

O treinamento para a aplicação do TDE teve duração em torno de 5 horas, incluindo trabalho teórico e prático, fornecido por dois psicólogos 
responsáveis também por supervisão local e por Skype uma vez que as entrevistas em campo foram iniciadas.

\subsubsection{Triagem para deficiência intelectual}

A fim de se ter deficiência intellectual como um critério de exclusão para TEA, o QI foi estimado através dos subtestes vocabulário e cubos [36, 53-54] de uma versão brasileira traduzida e validada do WISC-III [54], aplicados por psicólogos, todos previamente treinados pelo mesmo time de dois psicólogos aptos para realizar o treinamento. O treinamento teve duração de 4 horas, incluindo teoria e prática, além de suporte extra de supervisão local e à distância (por Skype).

\subsubsection{Investigação de correlatos sócio-demográficos}

Conforme já mencionado, o status sócio-econômico (SSE) da família foi avaliado por um questionário desenvolvido pela ABEP. Escores totais determinam o status sócio-econômico das famílias através de uma classificação de cinco classes sociais (A, B, C, D, E). Neste estudo, as classes foram agrupadas em três categorias: Média-Alta $(A, B)$, Média-Baixa $(C, D)$, e Baixa (E) [7].

Psicólogos treinados aplicaram o questionário para a mãe ou outro cuidador principal da criança ou adolescente.

Dois psicólogos previamente treinados foram responsáveis pelo treinamento de cada time de entrevistadores nas quatro cidades do estudo, assim como foram também os responsáveis pela supervisão local e por Skype, uma vez que as entrevistas em campo foram iniciadas. O treinamento total, teórico e prático, para o questionário, teve tempo total de 8 horas.

\subsubsection{Variáveis de confusão}

Alguns dados retirados das entrevistas foram avaliados como potenciais variáveis correlatas e com potencial de influenciar as taxas de prevalência: sexo, idade, QI, nível sócio-economico, região geográfica. 


\subsubsection{Análise estatística}

Foi realizada análise descritiva para a busca da prevalência dos transtornos mentais da infância e adolescência e dos problemas de aprendizagem. Análises de associação univariadas entre os transtornos de aprendizagem individuais ou categorizados e os transtornos mentais individuais ou categorizados foram feitas por teste de qui-quadrado enquanto que o teste-t foi realizado para as análises restantes com variáveis contínuas. Análises de regressão logística binária multivariada foram conduzidas para determinar os fatores associados com transtornos específicos de aprendizagem. Para as análises primárias deste estudo, as seguintes covariáveis demonstraram associação com transtorno de aprendizagem: gênero; idade; QI; SSE; e região geográfica. A concordância entre as diferentes abordagens diagnósticas para TEA (DSM-IV, DSM-5, normas brasileiras) foi avaliada pelo coeficiente de concordância Kappa. Valores abaixo de 0,2 indicam concordância pobre, de 0,2 a 0,39 regular, de 0,4 a 0,6 boa concordância e acima de 0,8 alta concordância [29]. O nível de significância utilizado foi 0.05 . Todas as análises foram realizadas utilizando o software SPSS, versão 20. 


\section{Resultados}

Usando o critério de 1,5 DP abaixo da média dos escores dos resultados do TDE, encontrou-se as seguintes taxas de prevalência de Transtorno Específico de Aprendizagem para as quatro cidades: 7,6\% para TEA com comprometimento global; $5,4 \%$ para TEA com comprometimento na escrita; 6,0\% para TEA com comprometimento na aritmética; e 7,5\% para TEA com comprometimento na leitura (Tabela 1). A perda amostral foi de 280 (14,0\%) sujeitos da amostra randomizada inicial de 2.000 crianças.

As diferenças entre as cidades foram significativas para TEA com comprometimento global e nas esferas de aprendizagem da escrita e leitura, como se pode observar na Tabela 1 ( $p$-valor $<0,001$ ). Para TEA com comprometimento na aritmética, não houve diferença significativa das prevalências entre as cidades. No TEA com comprometimento global, as análises post-hoc demonstraram que somente a cidade de Rio Preto da EvaAM era significativamente diferente das demais em termos de prevalência. No TEA com comprometimento na escrita, as prevalências em ambas cidades de Caeté-MG e Goianira-GO foram significativamente diferentes das cidades de Itaitinga-CE e Rio Preto da Eva-AM. No TEA com comprometimento na leitura, Caeté-MG apresentou uma taxa de prevalência significativamente diferente das cidades de Itaitinga-CE e Rio Preto da Eva-AM enquanto que Goianira-GO apresentou essa diferença somente com Rio Preto da Eva-AM. 
Tabela 1 - Prevalência de transtorno específico de aprendizagem com comprometimento global e na escrita, aritmética, e leitura*

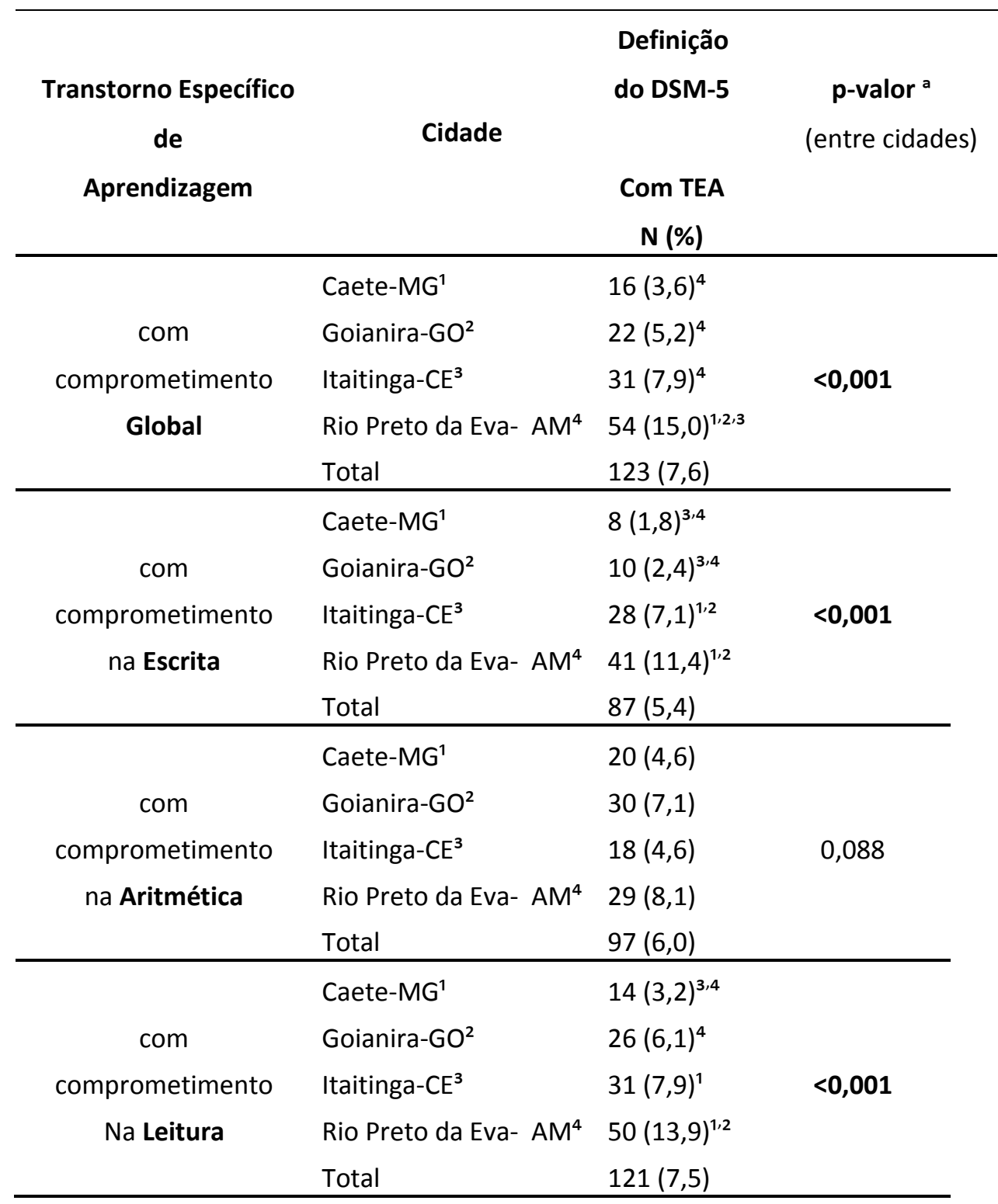

*usando 1,5 desvios-padrão (DP) abaixo da média dos escores dos subtestes de escrita, leitura, e aritmética do TDE estratificada na amostra por ano escolar. ${ }^{a} \mathrm{p}$-valor é do teste de Fisher para frequências. Os números sobreescritos na segunda e terceira coluna representam as cidades onde foram encontradas diferenças comparando a cidade de referência na linha das análises post-hoc.

Foram avaliados o perfil dos transtornos mentais comórbidos baseados na definição conservadora de TEA (de acordo com os critérios diagnósticos mais atuais, da $5^{a}$ edição do DSM), utilizando como contraste as médias calculadas para nossa amostra. Além disso, dados de prevalência das 
comorbidades das quatro cidades avaliadas podem ser vistos na Tabela 2. Poucos transtornos mentais apresentaram-se significativamente com mais freqüência nos indivíduos com TEA do que aqueles sem TEA (Tabela 2). A taxa de prevalência de TDAH foi significativamente mais alta para TEA com comprometimento global $(8,2 \% ; p$-valor $=0,031)$ e para TEA com comprometimento em aritmética (12,4\%; p-valor $<0,001)$. Os grupos Qualquer Transtorno Mental e Transtorno de Ansiedade foram significativamente mais associados com TEA com comprometimento em aritmética $(25,6 \%$ e p-valor $<0,001 ; 13,8 \%$ e p-valor $=0,008$, respectivamente) .

Tabela 2 - Prevalência de Comorbidades em Crianças e Adolescentes com TEA*

\begin{tabular}{|c|c|c|c|c|c|c|}
\hline \multirow{3}{*}{$\begin{array}{l}\text { Transtorno de } \\
\text { Aprendizagem }\end{array}$} & \multirow{3}{*}{$\begin{array}{c}\text { Grupo de Transtorno } \\
\text { Mental }\end{array}$} & \multirow{3}{*}{$\begin{array}{c}\text { Com } \\
\text { TEA } \\
\mathbf{N}\end{array}$} & \multirow{3}{*}{$\%$} & \multicolumn{2}{|l|}{ Sem } & \multirow{3}{*}{ p-valor } \\
\hline & & & & TEA & $\%$ & \\
\hline & & & & $\mathbf{N}$ & & \\
\hline & Transtorno de Ansiedade & 9 & 7,6 & 95 & 6,4 & 0,563 \\
\hline & Transtorno Alimentar & 0 & 0,0 & 2 & 0,1 & 1,000 \\
\hline com & Transtorno Psicótico & 0 & 0,0 & 2 & 0,1 & 1,000 \\
\hline comprometimento & Transtorno do Humor & 2 & 1,6 & 6 & 0,4 & 0,119 \\
\hline \multirow[t]{6}{*}{ Global } & Transtorno Disruptivo & 3 & 2,4 & 31 & 2,1 & 0,743 \\
\hline & TDAH & 10 & 8,2 & 57 & 3,8 & 0,031 \\
\hline & Transtorno de Tiques & 0 & 0,0 & 16 & 1,1 & 0,629 \\
\hline & Qualquer Transtorno Mental & 19 & 16,5 & 173 & 12,3 & 0,188 \\
\hline & Transtorno de Ansiedade & 7 & 8,1 & 97 & 6,4 & 0,500 \\
\hline & Transtorno Alimentar & 0 & 0,0 & 2 & 0,1 & 1,000 \\
\hline com & Transtorno Psicótico & 0 & 0,0 & 2 & 0,1 & 1,000 \\
\hline \multirow{7}{*}{$\begin{array}{c}\text { comprometimento } \\
\text { na Escrita }\end{array}$} & Transtorno do Humor & 2 & 2,3 & 6 & 0,4 & 0,066 \\
\hline & Transtorno Disruptivo & 2 & 2,3 & 32 & 2,1 & 0,709 \\
\hline & TDAH & 7 & 8,0 & 60 & 3,9 & 0,088 \\
\hline & Transtorno de Tiques & 0 & 0,0 & 16 & 1,1 & 1,000 \\
\hline & Qualquer Transtorno Mental & 14 & 16,9 & 178 & 12,3 & 0,233 \\
\hline & Transtorno de Ansiedade & 13 & 13,8 & 91 & 6,1 & 0,008 \\
\hline & Transtorno Alimentar & 0 & 0,0 & 2 & 0,1 & 1,000 \\
\hline com & Transtorno Psicótico & 0 & 0,0 & 2 & 0,1 & 1,000 \\
\hline \multirow{4}{*}{$\begin{array}{c}\text { comprometimento } \\
\text { na Aritmética }\end{array}$} & Transtorno do Humor & 2 & 2,1 & 6 & 0,4 & 0,079 \\
\hline & Transtorno Disruptivo & 3 & 3,1 & 31 & 2,1 & 0,456 \\
\hline & TDAH & 12 & 12,4 & 55 & 3,6 & $<0,001$ \\
\hline & Transtorno de Tiques & 1 & 1,0 & 15 & 1,1 & 1,000 \\
\hline
\end{tabular}




\begin{tabular}{|c|c|c|c|c|c|c|}
\hline & Qualquer Transtorno Mental & 23 & 25,6 & 169 & 11,8 & $<0,001$ \\
\hline & Transtorno de Ansiedade & 7 & 6,0 & 97 & 6,6 & 1,000 \\
\hline & Transtorno Alimentar & 0 & 0,0 & 2 & 0,1 & 1,000 \\
\hline com & Transtorno Psicótico & 0 & 0,0 & 2 & 0,1 & 1,000 \\
\hline comprometimento & Transtorno do Humor & 2 & 1,7 & 6 & 0,4 & 0,116 \\
\hline \multirow[t]{4}{*}{ na Leitura } & Transtorno Disruptivo & 3 & 2,5 & 31 & 2,1 & 0,740 \\
\hline & TDAH & 8 & 6,7 & 59 & 4,0 & 0,153 \\
\hline & Transtorno de Tiques & 0 & 0,0 & 16 & 1,1 & 0,626 \\
\hline & Qualquer Transtorno Mental & 16 & 14,2 & 176 & 12,5 & 0,558 \\
\hline
\end{tabular}

*usando 1,5 desvios-padrão (DP) abaixo da média dos escores dos subtestes de escrita, leitura, e aritmética do TDE na amostra por ano escolar. Além disso, é apresentado aqui os dados de comorbidades para as quatro cidades avaliadas.

As análises de regressão logística binária multivariada foram conduzidas para identificar os correlatos sócio-demográficos que podem estar associados com TEA. Novamente, a mesma estratégia de definição de TEA foi utilizada de maneira conservadora através das médias retiradas da nossa amostra e estratificadas por ano escolar. As taxas de prevalência de TEA foram calculadas a partir da média das quatro cidades. Todos correlatos avaliados (idade $(p=0,018)$, cidade $(p=0,004)$, status sócio-econômico $(p=0,007)$, gênero $(p=0,011)$, e $Q$ I $(p<0,001))$ foram significativamente associados com TEA com comprometimento em todas esferas de aprendizagem (Tabela 3), ou seja, com comprometimento global. Quando calculamos as mesmas análises para TEAs com comprometimentos específicos, encontraram-se os seguintes achados: TEA com comprometimento na leitura esteve significativamente associado à cidade $(p=0,003)$, gênero $(p=0,002)$, status sócio-econômico $(p=0,009)$ e Ql $(p<0,001)$; TEA com comprometimento em aritmética esteve significativamente associado ao QI $(p<0,001)$; e TEA com comprometimento na escrita esteve significativamente associado à idade $(p<0,001)$, gênero $(p=0,019)$, cidade ( $p=0,003)$, status sócio-econômico $(p=0,014)$ e QI $(p<0,001)$. 
Tabela 3 - Correlatos para TEA com comprometimento global em um Modelo de Regressão Logística*

\begin{tabular}{|c|c|c|c|c|c|c|c|c|}
\hline Yariónal* & 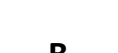 & 0 & Wold & -1 & cin & Fon(D) & \multicolumn{2}{|c|}{ 95\% I.C. para EXP(B) } \\
\hline QI Estimado & $-0,073$ & 0,011 & 41,687 & 1 & $<0,001$ & 0,929 & {$[0,909$} & $0,95]$ \\
\hline Cidade $^{1}$ & & & 13,172 & 3 & 0,004 & & & \\
\hline Goianira & 0,025 & 0,348 & 0,005 & 1 & 0,942 & 1,026 & 0,518 & 2,03 \\
\hline Itaitinga & 0,368 & 0,346 & 1,133 & 1 & 0,287 & 1,445 & 0,734 & 2,844 \\
\hline Rio Preto da Eva & 0,867 & 0,313 & 7,679 & 1 & 0,006 & 2,379 & 1,289 & 4,393 \\
\hline Idade & 0,127 & 0,053 & 5,644 & 1 & 0,018 & 1,135 & 1,022 & 1,26 \\
\hline $\begin{array}{l}\text { Gênero }^{2} \\
\text { (Masculino) }\end{array}$ & 0,525 & 0,206 & 6,482 & 1 & 0,011 & 1,69 & 1,128 & 2,53 \\
\hline Classe Social $^{3}$ & & & 9,939 & 2 & 0,007 & & & \\
\hline Classe Social C & 0,416 & 0,551 & 0,568 & 1 & 0,451 & 1,515 & 0,514 & 4,464 \\
\hline Classe Social D/E & 1,024 & 0,548 & 3,496 & 1 & 0,062 & 2,786 & 0,952 & 8,152 \\
\hline Constante & 1,416 & 1,342 & 1,113 & 1 & 0,291 & 4,12 & & \\
\hline
\end{tabular}

*Variáveis que entraram no $1^{\circ}$ passo: QI Estimado, Cidade, Ano, Gênero e Classe Social. TEA foi definido usando1,5 DP abaixo da média dos escores do TDE estratificada por ano na amostra.

\footnotetext{
${ }^{1}$ Cidade usada como contraste: Caeté

${ }^{2}$ Gênero usado como contraste: Feminino

${ }^{3}$ Classe Social usada como contraste: A/B

E.P. $=$ Erro padrão
}

$\mathrm{Na}$ Tabela 4 abaixo, evidenciam-se diferentes prevalências de TEA, tanto com comprometimento global quanto com comprometimento nas esferas individuais da escrita, aritmética, e leitura, quando usamos os diferentes critérios diagnósticos das duas versões do DSM: DSM-IV e DSM-5.

Usando os critérios da DSM-IV, somente as cidades de Caeté-MG e Itaitinga-CE eram significativamente diferentes uma da outra em termos de prevalência no TEA com comprometimento global. No TEA com comprometimento na escrita, as prevalências nas cidades de Goianira-GO e Itaitinga-CE foram significativamente diferentes de Caeté-MG. No TEA com comprometimento na aritmética, nao houve diferença estatisticamente significante entre as cidades. No TEA com comprometimento na leitura, Caeté- 
MG apresentou uma taxa de prevalência significativamente diferente das cidades de Itaitinga-CE e Rio Preto da Eva-AM.

Tabela 4 - Comparação de prevalências entre os diferentes critérios diagnósticos do DSM-IV e DSM-5 para Transtorno Específico de Aprendizagem (TEA) de Crianças e Adolescentes

\begin{tabular}{|c|c|c|c|c|c|c|}
\hline $\begin{array}{c}\text { Transtorno } \\
\text { Específico } \\
\text { de Aprendizagem }\end{array}$ & Cidade & $\begin{array}{c}\text { Definição } \\
\text { pela DSM-5 } \\
\text { Com TEA } \\
\text { N (\%) }\end{array}$ & $\begin{array}{l}\text { p-valor a } \\
\text { (entre } \\
\text { cidades) }\end{array}$ & $\begin{array}{c}\text { Definição } \\
\text { pela DSM-IV } \\
\text { Com TEA } \\
\mathbf{N}(\%)\end{array}$ & $\begin{array}{l}\text { p-valor a } \\
\text { (entre } \\
\text { cidades) }\end{array}$ & $\begin{array}{c}\text { coeficiente de } \\
\text { concordância } \\
\text { kappa }\end{array}$ \\
\hline com & Caete-MG ${ }^{1}$ & $16(3,6)^{4}$ & & $9(2,0)^{3}$ & & 0,302 \\
\hline comprometimento & Goianira-GO² & $22(5,2)^{4}$ & & $13(\mathbf{3}, \mathbf{1})$ & & 0,198 \\
\hline \multirow[t]{3}{*}{ Global } & Itaitinga- $\mathrm{CE}^{3}$ & $31(7,9)^{4}$ & $<0,001$ & $20(5,1)^{1}$ & 0,090 & 0,436 \\
\hline & Rio Preto da Eva- $\mathrm{AM}^{4}$ & $54(15,0)^{1,2,3}$ & & $15(4,2)$ & & 0,240 \\
\hline & Total & $123(7,6)$ & & $57(3,5)$ & & 0,300 \\
\hline com & Caete-MG ${ }^{1}$ & $8(1,8)^{3,4}$ & & $5(1,1)^{2,3}$ & & $<0$ \\
\hline comprometimento & Goianira-GO ${ }^{2}$ & $10(2,4)^{3,4}$ & & $14(3,3)^{1}$ & & 0,143 \\
\hline \multirow[t]{3}{*}{ na Escrita } & Itaitinga- $\mathrm{CE}^{3}$ & $28(7,1)^{1,2}$ & $<0,001$ & $15(3,8)^{1}$ & 0,063 & 0,192 \\
\hline & Rio Preto da Eva- $\mathrm{AM}^{4}$ & $41(\mathbf{1 1 , 4})^{1,2}$ & & $10(2,8)$ & & 0,076 \\
\hline & Total & $87(5,4)$ & & $44(2,7)$ & & 0,121 \\
\hline com & Caete-MG ${ }^{1}$ & $20(4,6)$ & & $13(3,0)$ & & 0,089 \\
\hline comprometimento & Goianira-GO² & $30(7,1)$ & & $14(3,3)$ & & 0,143 \\
\hline \multirow[t]{3}{*}{ na Aritmética } & Itaitinga- $\mathrm{CE}^{3}$ & $18(4,6)$ & 0,088 & $18(4,6)$ & 0,580 & 0,185 \\
\hline & Rio Preto da Eva- $\mathrm{AM}^{4}$ & $29(8,1)$ & & $15(4,2)$ & & 0,134 \\
\hline & Total & $97(6,0)$ & & $60(3,7)$ & & 0,139 \\
\hline com & Caete-MG ${ }^{1}$ & $14(3,2)^{3,4}$ & & $9(2,0)^{3,4}$ & & 0,331 \\
\hline comprometimento & Goianira-GO² & $26(6,1)^{4}$ & & $17(4,0)$ & & 0,291 \\
\hline \multirow[t]{3}{*}{ na Leitura } & Itaitinga- $\mathrm{CE}^{3}$ & $31(7,9)^{1}$ & $<0,001$ & $25(6,4)^{1}$ & 0,011 & 0,462 \\
\hline & Rio Preto da Eva- $\mathrm{AM}^{4}$ & $50(13,9)^{1,2}$ & & $19(5,3)^{1}$ & & 0,388 \\
\hline & Total & $121(7,5)$ & & $70(4,3)$ & & 0,385 \\
\hline
\end{tabular}

${ }^{a} \mathrm{p}$-valor é do teste de Fisher para frequências.

Os números sobreescritos $\left(^{1,2,3,4}\right)$ na terceira e quinta coluna representam as cidades onde foram encontradas diferenças comparando a cidade de referência (segunda coluna) na linha das análises post-hoc.

Como se pode observar na Tabela 5 abaixo, foram encontradas taxas de prevalência significativamente mais altas quando a definição do Transtorno 
Específico de Aprendizagem foi baseada em normas fornecidas pelo manual do TDE, do que quando baseada nas médias dos escores da nossa amostra.

No TEA com comprometimento global, todas as cidades eram significativamente diferentes uma das outras em termos de prevalência. No TEA com comprometimento na escrita, ambas as cidades de Itaitinga-CE e Rio Preto da Eva-AM apresentaram prevalências estatisticamente diferentes das restantes enquanto que Caeté-MG e Goianira-GO demonstraram prevalências significativamente diferentes somente de Itaitinga-CE e Rio Preto da Eva-AM.

No TEA com comprometimento na aritmética, Rio Preto da Eva-AM foi a cidade estatisticamente diferente de todas as outras cidades; enquanto que Caeté-MG apresentou prevalência estatisticamente diferente das cidades de Itaitinga-CE e Rio Preto da Eva-AM. No TEA com comprometimento na leitura, Itaitinga-CE e Rio Preto da Eva-AM apresentaram prevalências estatisticamente diferentes das outras cidades, enquanto que Caeté-MG e Goianira-GO demonstraram prevalências significativamente diferentes somente de Itaitinga-CE e Rio Preto da Eva-AM.

Tabela 5 - Comparação de prevalências entre os critérios diagnósticos do DSM-5 e "Normas Brasileiras" para Transtorno Específico de Aprendizagem (TEA) de Crianças e Adolescentes

\begin{tabular}{|c|c|c|c|c|c|c|}
\hline $\begin{array}{c}\text { Transtorno } \\
\text { Específico } \\
\text { de Aprendizagem }\end{array}$ & Cidade & $\begin{array}{c}\text { Definição } \\
\text { pela DSM-5 } \\
\text { Com TEA }\end{array}$ & $\begin{array}{l}\text { p-valor }{ }^{\text {a }} \\
\text { (entre } \\
\text { cidades) }\end{array}$ & $\begin{array}{l}\text { Normas } \\
\text { Brasileiras } \\
\text { Com TEA }\end{array}$ & $\begin{array}{l}\text { p-valor a } \\
\text { (entre } \\
\text { cidades) }\end{array}$ & $\begin{array}{c}\text { coeficiente de } \\
\text { concordância } \\
\text { kappa }\end{array}$ \\
\hline de Aprendizagem & & $\mathbf{N}(\%)$ & & $\mathbf{N}(\%)$ & & \\
\hline com & Caete-MG ${ }^{1}$ & $16(3,6)^{4}$ & & $106(24,1)^{234}$ & & 0,302 \\
\hline comprometimento & Goianira-GO² & $22(5,2)^{4}$ & & $137(32,2)^{134}$ & & 0,198 \\
\hline \multirow[t]{3}{*}{ Global } & Itaitinga- $\mathrm{CE}^{3}$ & $31(7,9)^{4}$ & $<0,001$ & $179(45,5)^{124}$ & $<0,001$ & 0,436 \\
\hline & Rio Preto da Eva-AM ${ }^{4}$ & $54(15,0)^{123}$ & & $224(62,2)^{123}$ & & 0,24 \\
\hline & Total & $123(7,6)$ & & $646(39,9)$ & & 0,3 \\
\hline com & Caete-MG ${ }^{1}$ & $8(1,8)^{34}$ & & $119(27,0)^{34}$ & & $-0,014$ \\
\hline comprometimento & Goianira-GO² & $10(2,35)^{34}$ & & $147(34,6)^{34}$ & & 0,143 \\
\hline na Escrita & Itaitinga- $\mathrm{CE}^{3}$ & $28(7,12)^{12}$ & $<0,001$ & $188(47,8)^{124}$ & $<0,001$ & 0,192 \\
\hline
\end{tabular}




\begin{tabular}{|c|c|c|c|c|c|c|}
\hline & \multirow{2}{*}{$\begin{array}{l}\text { Rio Preto da Eva-AM } \\
\text { Total }\end{array}$} & \multicolumn{2}{|l|}{$41(11,39)^{12}$} & \multicolumn{2}{|l|}{$228(63,3)^{123}$} & \multirow{2}{*}{$\begin{array}{l}0,076 \\
0,121\end{array}$} \\
\hline & & $87(5,38)$ & & $682(42,2)$ & & \\
\hline com & Caete-MG ${ }^{1}$ & $20(4,55)$ & & $78(17,7)^{34}$ & & 0,089 \\
\hline comprometimento & Goianira-GO² & $30(7,06)$ & & $104(24,5)^{4}$ & & 0,143 \\
\hline \multirow[t]{3}{*}{ na Aritmética } & Itaitinga-CE ${ }^{3}$ & $18(4,58)$ & 0,088 & $124(31,6)^{14}$ & $<0,001$ & 0,185 \\
\hline & Rio Preto da Eva-AM ${ }^{4}$ & $29(8,06)$ & & $145(40,3)^{123}$ & & 0,134 \\
\hline & Total & $97(6,00)$ & & $451(27,9)$ & & 0,139 \\
\hline com & Caete-MG' & $14(3,18)^{34}$ & & $96(21,8)^{34}$ & & 0,331 \\
\hline comprometimento & Goianira-GO² & $26(6,12)^{4}$ & & $107(25,2)^{34}$ & & 0,291 \\
\hline \multirow[t]{3}{*}{ na Leitura } & Itaitinga- $\mathrm{CE}^{3}$ & $31(7,89)^{1}$ & $<0,001$ & $139(35,4)^{124}$ & $<0,001$ & 0,462 \\
\hline & Rio Preto da Eva-AM ${ }^{4}$ & $50(13,89)^{12}$ & & $166(46,1)^{123}$ & & 0,388 \\
\hline & Total & $121(7,48)$ & & $508(31,4)$ & & 0,385 \\
\hline
\end{tabular}

${ }^{a}$ p-valor é do teste de Fisher para frequências.

Os números sobreescritos $\left({ }^{1,2,3,4}\right)$ na terceira e quinta coluna representam as cidades onde foram encontradas diferenças comparando a cidade de referência (segunda coluna) na linha das análises post-hoc.

Os coeficientes kappa nas tabelas 4 e 5 permitem observar que os coeficientes kappa totais não atingiram uma concordância pelo menos moderada para nenhuma tipificação de TEA. 


\section{Discussão}

\subsection{Similaridade dos achados de prevalência com estudos prévios}

\subsubsection{Transtorno de Aprendizagem}

Encontrou-se taxas de prevalências de TEAs similares àquelas apresentadas em estudos prévios: 7,6\% para TEA com comprometimento em todas as esferas de aprendizagem (leitura, escrita, e aritmética), ou seja, aquela que chamamos de comprometimento global; $5,4 \%$ para TEA com comprometimento na escrita; $6,0 \%$ para TEA com comprometimento na aritmética; e 7,5\% para TEA com comprometimento na leitura, quando todas as quatro cidades que participaram do estudo foram consideradas. Todos correlatos sócio-demográficos (idade, cidade, status sócio-econômico, gênero, e Ql) investigados foram associados na nossa amostra ao TEA com comprometimento global.

É extremamente difícil realizar a comparação entre as nossas taxas de prevalência de TEA com aquelas de estudos prévios considerando a grande variedade de terminologia [59] e diversidade nas metodologias aplicadas nos diferentes estudos [16]. Entretanto, Al-Yagon et al. [2] foram capazes de apresentar os efeitos propostos pelas mudanças do novo manual diagnóstico dos transtornos mentais, o DSM-5, no diagnóstico do TEA, em dez diferentes países, incluindo países de baixa e média renda, providenciando assim, uma perspectiva internacional do TEA. Esses investigadores demonstraram diferenças importantes nas taxas de prevalência entre os países, que variaram de $1,2 \%$ a $20,0 \%$. Os autores enfatizam que as imensas diferenças entre os critérios diagnósticos, características de linguagem, fundamentos legislativos, políticas educacionais, e no uso do Manual Diagnóstico e Estatístico dos Transtornos Mentais (DSM) podem justificar a heterogeneidade das taxas encontradas. Vale ressaltar que muitos profissionais de saúde mental e profissionais que trabalham na rede escolar nunca se utilizaram nem da versão anterior do manual, o DSM-IV, para o diagnóstico de TEA, sendo esta prática ausente principalmente em países de baixa e média renda em comparação aos 
países desenvolvidos. Assim, os autores relataram uma taxa de prevalência na Alemanha de $4,0 \%$ a $8,0 \%$ de estudantes com TEA com comprometimento na leitura e $4,0 \%$ a $6,0 \%$ com comprometimento em aritmética e dados que apresentam até $10,0 \%$ de sinais de TEA com comprometimento global [2]. Mesmo o Brasil sendo um país de menor renda em comparação à Alemanha, os dados de prevalência que obtivemos em nosso estudo (7,5\%; $6,0 \%$; e $7,6 \%$, respectivamente) condizem com os mencionados acima, menos a taxa que encontramos do TEA com comprometimento na leitura, que ultrapassa em $1,5 \%$ a encontrada nos bancos de dados alemãos. Já em comparação à Grécia, obtivemos taxas bem mais altas do que as taxas de prevalência de TEA com comprometimneto global encontradas, que variam de 1,2\% em 2004 para 1,6\% em 2005, baseado em estudos epidemiológicos e relatórios governamentais gregos, sendo estes os únicos dados disponíveis e encontrados pelos autores [2].

Nossa taxa de prevalência de TEA em todas as esferas da aprendizagem, ou seja, com comprometimento global incluindo a leitura, escrita e aritmética, foi de $7,6 \%$ e se encaixa na variação proposta pelo DSM-5 [5], que aponta para taxas de prevalência dentro da faixa de 5,0\% a 15,0\%, concordando também com as taxas de prevalência apresentadas em outros estudos [12]. Existe uma heterogeneidade importante nas taxas de prevalência [2] não somente entre países, mas também entre estados e regiões dentro de um mesmo país, assim como é demonstrado em nosso estudo.

Nossa taxa de prevalência de TEA com comprometimento especificamente na esfera da leitura é de $7,5 \%$, sendo muito similar à nossa taxa previamente citada, de TEA em todas as esferas da aprendizagem (7,6\%) assim como também aparece de forma consistente com estudos prévios de prevalência. Sexton et al. (2012) [49] relatam uma variação na taxa de prevalência de $4,0 \%$ a $10,0 \%$ de TEA com comprometimento específico na esfera da leitura em cinco diferentes estudos, enquanto que Scerri et al. (2010) [50] relatam que este comprometimento da leitura se encontra presente em pelo menos 5,0\% das crianças de idade escolar. Landerl e Moll (2010) [28] encontraram uma prevalência de TEA com comprometimento na esfera da leitura de $7,0 \%$, muito similar ao nossos achados. 
Em relação ao TEA com comprometimento específico na esfera da escrita, nossa prevalência de $5,4 \%$ se apresenta mais baixa do que os achados de um estudo na Cidade Indiana do Sul (South Indian City), que foi de 12,5\% [38] e de um estudo em escolas austríacas, que foi de $8,8 \%$, considerando que o último incluiu somente o subtipo transtorno do soletramento do DSM-IV [28].

Nossa prevalência de $6,0 \%$ de TEA com comprometimento especificamente na esfera da aritmética apresenta-se muito similar aos achados anteriores, incluindo um estudo em escolas austríacas que encontrou uma taxa de prevalência de 6,1\% [28]. Uma prevalência de 6,4\% foi encontrada em amostra de alunos do 50 ano em um estudo na Bratislava assim como em amostra americana de estudantes do $1^{\circ}$ ao $8^{\circ}$ ano; e dois outros estudos em Berlin que apresentam a mesma taxa de prevalência de 6,6\% na amostra [51]. No entanto, países tendem a apresentar variações nestas taxas de prevalência, que parecem oscilar entre $3,0 \%$ e $6,0 \%$ [51].

\subsubsection{Comorbidades}

O TDAH foi o único transtorno mental comórbido significativamente associado ao TEA com comprometimento em todas as esferas de aprendizagem (leitura, escrita, e aritmética). Dentre as esferas de aprendizagem, de acordo com os resultados dos subtestes do TDE, a única que apresentou taxas de comorbidade mais altas e com associação significativa foi a TEA com comprometimento na esfera da aritmética.

Inúmeros pesquisadores descrevem a coexistência frequente entre TDAH e TEA [5, 14-17, 32-34, 45-46, 49, 55, 63] e que esta forte associação pode levar ao aumento do risco de outras psicopatologias [34]. Nossos achados de comorbidade entre TEA e TDAH são consistentes com a literatura. McGillivray e Baker (2009) [34] enfatizam a probabilidade da co-ocorrência de TDAH e TEA através dos seus achados, defendendo que o diagnóstico de ambos transtornos juntos acontece de maneira significativamente mais frequente do que o de TDAH sozinho. Capozzi et al. (2008) [14] também encontraram achados que mostram que sintomas de TDAH são mais prevalentes em crianças com TEA e relataram que de acordo com diferentes 
estudos a prevalência de TDAH na população com TEA pode variar de 15,0\% a 25,0\%, enquanto que Du Paul et al. (2013) [16] apontam que aproximadamente $31,0 \%$ a 45,0\% de estudantes com TEA também apresentam TDAH. Apesar de estatisticamente significativa, a taxa de prevalência comórbida encontrada no nosso estudo de TDAH (8,2\%) na amostra de TEA com comprometimento global, ou seja, em todas as esferas de aprendizagem (leitura, escrita e aritmética), foi mais baixa do que os achados citados acima.

$\mathrm{Na}$ nossa amostra, o grupo de TEA com comprometimento na area da aritmética também foi significativamente associado com os seguintes grupos de comorbidades: TDAH, Qualquer Transtorno de Ansiedade, e Qualquer Transtorno Mental, o que reforça achados similares de estudos prévios [63]. Von Aster e Shalev (2007) [63] sugerem a presença de uma importante associação entre TEA com comprometimento na aritmética e transtorno de ansiedade, assim como TEA e TDAH, como foi evidenciado também em nosso estudo.

\subsection{Similaridade dos achados de correlatos com estudos prévios}

Como evidenciado em nosso estudo, o QI foi significativamente associado com o TEA, mesmo no contexto de outros correlatos. Altarac e Saroha [3] encontraram que, através da investigação da prevalência de TEA ao longo da vida em crianças dos Estados Unidos, certas variáveis sóciodemográficas (aumento de idade, o sexo masculino, baixa educação do núcleo familiar, e todas as categorias de pobreza) foram associadas com maiores chances de apresentar um transtorno específico de aprendizagem ao longo da vida [3]. Estes achados concordam fortemente com os nossos em relação a idade, gênero, e status sócio-econômico. Em relação a gênero, Rutter et al. (2004) também encontraram na amostra de TEA com comprometimento na área da leitura taxas de prevalência significativamente mais altas no sexo masculino, mesmo considerando ou não o QI [47].

Para acrescentar, as cidades foram significativamente associadas com a presença do TEA mesmo no contexto de outros correlatos como QI, status sócio-econômico, gênero, e idade. Dados de prevalência de TEA de acordo 
com diferenças regionais dentro dos países não foram encontrados para comparação.

\subsection{Comparação das prevalências de acordo com definições do DSM- IV e DSM-5}

A diferença das prevalências de TEA entre as cidades foi maior pelos critérios do DSM-5 do que pelos critérios do DSM-IV. Os diferentes métodos demonstram um perfil similar porém não igual das pessoas consideradas como tendo TEA. Muitas crianças e adolescentes não são os mesmos, o que pode ser explicado pela discrepância grande entre os dois métodos (demonstrado pelo valor de kappa), o que leva indivíduos a passarem no ponto de corte de uma definição e não de outra, como demonstram as tabelas 7, 8, 9, e 10 (em anexo).

No DSM-IV, um ponto central para o diagnóstico é a diferença dos escores individuais de QI e desempenho das esferas escolares, ambos em relação a uma média populacional. Considera-se TEA apenas nos casos em que o desempenho em uma das esferas escolares está 2 DP abaixo do desempenho de QI do indivíduo. No DSM-5, a média do desempenho acadêmico de toda a amostra é usada como parâmetro para comparação do desempenho de cada indivíduo. Define-se como TEA um desempenho 1,5 DPs abaixo da média populacional em uma esfera escolar.

O produto dessa diferença conceitual pode ser visto na variação das taxas de prevalência de TEA entre as cidades desse estudo conforme a definição diagnóstica. Rio Preto da Eva de acordo com o DSM-5, por exemplo, é a cidade com as prevalências mais altas de TEA, não importa a esfera de aprendizado. No entanto, realizando os cálculos de prevalência de TEA pelo DSM-IV, Itaitinga passa a ser a cidade com maiores taxas de prevalência. Uma hipótese para essa diferença na avaliação da cidade com maior prevalência de TEA é que Rio Preto da Eva é a cidade com pior média de QI da amostra (média de $\mathrm{QI}=88,9$ ) (vide Tabela 11 no anexo), impossibilitando que muitas crianças apresentem um desempenho em leitura, escrita ou matemática que 
possa ser 2 DP piores do que o seu desempenho em QI em relação a amostra total.

A escolha dos critérios do DSM-5 para a maioria das nossas análises se deve aos seguintes motivos: a) representam os parâmetros mais atuais da pesquisa internacional; b) eles não consideram a discrepância de QI como fundamental para o diagnóstico. Assim, podemos chegar mais próximos do cenário real em termos de taxas de prevalência (em comparação ao DSM-IV) de crianças e adolescentes que sofrem com TEA. Somente através de dados mais realistas podemos chamar atenção daqueles responsáveis em promover políticas públicas no nosso país.

É razoável esperar, portanto, que os novos critérios diagnósticos para TEA no DSM-5 possam aumentar a taxa de prevalência do TEA, especialmente através da eliminação do critério de discrepância de desempenho do QI (IQachievement discrepancy criterion) [2]. No DSM-IV, com este critério que tornava mais restrito o diagnóstico do TEA, menos crianças eram diagnosticadas, levando em consideração que aquelas com baixo QI eram subdiagnosticadas.

\section{4 "Normas Brasileiras"}

Não há instrumento algum para triagem de transtorno específico de aprendizagem que seja padronizado para a população brasileira. O Brasil, sendo um país heterogêneo, possui muitas desigualdades entre suas regiões geográficas e mesmo dentro de cada região é possível se evidenciar as diferentes classes sociais, econômicas, e nível de instrução escolar.

Além disso, através do nosso estudo, documentamos que as taxas de prevalência de TEA usando o que chamamos de "Normas Brasileiras" do TDE, com as médias e desvios-padrão calculados a partir da amostra do teste, foram significativamente mais altas do que aquelas que foram baseadas nas médias estratificadas por ano escolar da nossa amostra. Dessa forma, enfatiza-se os riscos de se usar normas não adequadamente validadas em amostras representativas do país, especialmente em países geograficamente amplos como o Brasil, caracterizados por grandes desigualdades. 
Taxas de prevalência de TEA com comprometimento global ou em qualquer esfera da aprendizagem foram significativamente mais altas em todas as cidades quando a definição do TEA era baseada nas "Normas Brasileiras", ou seja, nas tabelas fornecidas pelo manual do TDE.

Nossos achados reforçam a extrema relevância de existirem dados normativos reais para TEA com base em amostras que sejam de fato representativas do país em questão, enfatizando esta necessidade principalmente para os países de baixa e média renda, onde estudos representativos para a construção de instrumentos que auxiliem o diagnóstico dos transtornos mentais ainda são escassos. A grande maioria dos países de baixa e média renda (PBMR) não possuem quaisquer dados normativos validados sobre o desempenho acadêmico geral tanto em relação à leitura, escrita, e/ou aritmética na população de seus estudantes, tornando as estimativas do TEA uma tarefa difícil nestes países. Dados normativos reais de prevalência permitem a elaboração planejada de intervenções no âmbito da saúde mental em PBMR para que esta seja efetivamente colocada em prática. A falta de estudos de prevalência baseados na população em questão nos PBMR contribui para a existência de barreiras para a intervenção, prejudicando desde o seu planejamento até a sua realização [11]. Bruckner et al. (2011) demonstram que $100 \%$ dos países de baixa renda e 59\% dos de média renda de sua amostra apresentam um número muito abaixo do necessário de profissionais de saúde mental (há uma falta de 239.000 profissionais) para suprir com as demandas de intervenção [11].

\subsection{Limitações}

Nosso estudo deve ser entendido no contexto de algumas limitações. Primeiramente, a região sul não foi incluída e desta forma não foi possível realizar a investigação epidemiológica em todo Brasil, sendo o sul a única região geográfica excluída do estudo. Assim, devido à dificuldades financeiras para expandir o estudo para todas as cinco regiões, foi-se necessário a escolha 
de quatro das cinco regiões onde pesquisas epidemiológicas são evidentemente mais escassas.

Além disso, não foi possível realizarmos uma avaliação completa do QI, calculando apenas o Ql estimado, através de somente dois subtestes do WISC-III [65]. Entretanto, esta estratégia tem sido utilizada por inúmeros estudos populacionais [36, 40, 53, 62] e as normas de Wechsler permitem o uso de dois subtestes para o propósito de triagem [54]. A escolha dos subtestes utilizados, vocabulário e cubos, para o cálculo do QI estimado foi frequentemente feita em estudos prévios, também para o mesmo propósito.

O time de psicólogos que foram treinados se modificou ao longo do estudo, havendo diferentes grupos para as quatro cidades do estudo, aumentando as chances de problemas de confiabilidade. Além disso, não foi avaliada a confiabilidade entre entrevistadores. No entanto, os dois psicólogos responsáveis pelo treinamento de todos os grupos de psicólogos, escolhidos para serem os entrevistadores dos estudos, foram os mesmos durante todo a realização do estudo, ou seja, para as quatro cidades, minimizando este efeito.

Tivemos uma perda amostral de 14,0\%, mas que por ser um estudo transversal de associação, pode ser considerada pequena. Além disso, algumas famílias foram extremamente difíceis de serem encontradas, por exemplo: no estado do Amazonas algumas delas eram somente alcançadas através de barco e, além disso, uma enchente ocorreu no final do estudo, o que restringiu a chegada das famílias restantes ao local das entrevistas.

A avaliação de todos critérios para TEA do novo manual do DSM-5 não foi realizada. Como o estudo realizado foi um estudo transversal, foi impossível obter informações a respeito da duração dos déficits no desempenho acadêmico geral da criança ou adolescente, assim como nas esferas da leitura, escrita, e/ou aritmética. Além disso, não conseguimos saber se os casos em potencial receberam anteriormente qualquer intervenção baseada em evidência. Porém, este estudo adotou a definição mais próxima possível aos critérios do DSM-5 em uma pesquisa epidemiológica em um país em desenvolvimento. Vale ressaltar que o critério que demanda a necessidade de intervenção anterior para diagnóstico de TEA tem sido criticado por dificultar o diagnóstico, principalmente em crianças e adolescentes em pior situação sócio- 
econômica. Além disso, não há critérios diagnósticos para qualquer outro transtorno mental que exija uma intervenção como parte da definição diagnóstica. Por fim, nossas taxas de prevalência não são baseadas em normas derivadas de amostras representativas da nossa população, como foi extensivamente e previamente discutido.

Assim, existe uma importante e clara necessidade para a normatização dos instrumentos para medir e avaliar o TEA em todas as suas esferas de aprendizagem, ou seja, na leitura, escrita, e aritmética, em todo o mundo, sendo este desafio especialmente maior para os países em desenvolvimento. No Brasil, um país geograficamente extenso e com indiscutíveis desigualdades e diversidades, a falta de um instrumento padronizado para detectar o TEA dificulta fortemente a avaliação do real cenário das crianças e adolescentes brasileiros na escola. Mesmo assim, nossos achados sugerem taxas de prevalência de TEA, assim como o perfil tanto dos transtornos mentais comórbidos quanto dos correlatos sócio-demográficos muito similares àqueles detectados em estudos internacionais prévios.

Embora fizesse parte do projeto inicial, não foi possível avaliar o impacto dos TEA nas repetências escolares, uma vez que no Brasil as crianças e adolescentes não repetem mais de ano nas primeiras/os séries/anos do ensino público. Dos 41 países que compõem a região da América Latina e Caribe, o Brasil possui a maior taxa de repetência na educação básica: 18,7\% [61]. Assim, pode-se dizer que os indivíduos que repetem de ano apresentam pior desempenho escolar e sugere-se que a prevalência de dificuldades de aprendizagem e possíveis transtornos de aprendizagem seja maior neste grupo do que no de não-repetentes. 


\section{Conclusão}

Em todas as quatro cidades do estudo, em Itaitinga (CE), Goianira (GO), Caeté (MG), e Rio Preto da Eva (AM), detectou-se taxas de prevalência de TEA significativas, o que demonstra a importância do problema e a necessidade do diagnóstico precoce deste transtorno. Assim, é possível concluir que a orientação para professores em sala de aula e para pais é essencial para que haja o diagnóstico precoce a fim de que as crianças e adolescentes sejam encaminhados para o tratamento necessário.

Como esperado, foi encontrado também uma grande heterogeneidade nas taxas de prevalência de Transtorno Específico de Aprendizagem entre as diferentes regiões geográficas do Brasil, sendo este um país com forte diversidade. Transtorno Específico de Aprendizagem com comprometimento global e em aritmética foram significativamente associados com comorbidades psiquiátricas, especificamente TDAH e o grupo dos Transtornos de Ansiedade.

A validação e normatização de instrumentos que avaliem o desempenho acadêmico, tanto em relação ao comprometimento global quanto para as esferas específicas de aprendizagem - leitura, escrita, e aritmética - é ainda um grande problema em inúmeros países, o que pôde também ser evidenciado neste trabalho para o Brasil. 


\section{Anexo A - Escolas do Brasil}

Tabela 6 - Número de estabelecimentos de ensino fundamental, total e em área urbana, por etapa e dependência administrativa, segundo as Grandes Regiões e as Unidades da Federação - 2012

Grandes Número de estabelecimentos de ensino fundamental, total e em área urbana, por etapa Regiões e dependência administrativa

e Total (1) Urbana

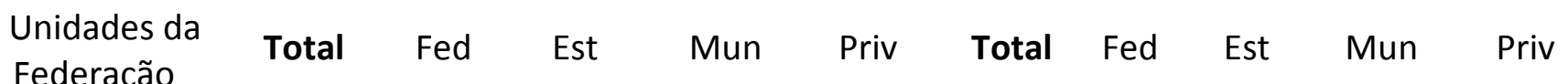

\section{Brasil}

144705

46

2574996921

2198975938

45

20839

33364

21690

\section{Norte}

Rondônia

Acre

Amazonas

Roraima

Pará

Amapá

Tocantins

Nordeste

Maranhão

Piauí

Ceará

Rio Grande do N

Paraíba

Pernambuco

Alagoas

Sergipe

Bahia

Sudeste
Minas Gerais
Espírito Santo
Rio de Janeiro
São Paulo

Sul

São Paulo

$\begin{array}{rr}21150 & 5 \\ 1152 & 0 \\ 1536 & 1 \\ 5079 & 1 \\ 627 & 1 \\ 10586 & 2 \\ 695 & 0 \\ 1475 & 0\end{array}$

$63344 \quad 10$

11428

$5277 \quad 1$

$6847 \quad 1$

$3027 \quad 1$

$5174 \quad 1$

$8843 \quad 2$

$2825 \quad 0$

19941

$17929 \quad 1$

$\begin{array}{rr}\mathbf{3 4 2 6} & \mathbf{1 6} \mathbf{5 7 7} \\ 376 & 684 \\ 607 & 909 \\ 536 & 4348 \\ 369 & 236 \\ 681 & 9241 \\ 388 & 268 \\ 469 & 891\end{array}$

$4977 \quad 49853$

64110161

$457 \quad 4455$

$267 \quad 5164$

5631963

$682 \quad 3722$

$883 \quad 5999$

$264 \quad 2109$

$343 \quad 1342$

$877 \quad 14938$
$8504 \quad 24557$

$624 \quad 2683$

3641663

$1415 \quad 3503$

$500 \quad 1556$

769

1959

452

308

2113

2258

\section{$5 \quad 1894$}

262

145

446

79

487

128

347
2765

186

101

529

72

1460

91

326
1111

88

19

187

21

647

35

114

\section{$37061 \quad 23$}

11831

2401

7831

14998
$9623 \quad 18242$

$3305 \quad 6798$

461

969

1713

3732

4888

5999
$9173 \quad 29187$

$1723 \quad 7422$

227

1219

3113

6704

$4110 \quad 13842$
9

$$
1
$$

4050

12152

311

1786

8346

1

449

854

585

1

236

470

1863

593

1403

1

552

943

492

762 


\begin{tabular}{|c|c|c|c|c|c|c|c|c|c|c|}
\hline $\begin{array}{l}\text { Paraná } \\
\text { Santa }\end{array}$ & 6018 & 1 & 1922 & 3280 & 815 & 4537 & 1 & 1497 & 2231 & 808 \\
\hline Catarina & 3376 & 1 & 982 & 2029 & 364 & 2307 & 1 & 791 & 1151 & 364 \\
\hline Rio Grande do S & 6400 & 3 & 2379 & 3561 & 457 & 3926 & 3 & 1729 & 1742 & 452 \\
\hline Centro-Oeste & 7356 & 3 & 2440 & 3379 & 1534 & 5649 & 3 & 2084 & 2041 & 1521 \\
\hline Mato Grosso do S & 1076 & 1 & 325 & 537 & 213 & 866 & 1 & 291 & 363 & 211 \\
\hline Mato Grosso & 1990 & 0 & 633 & 1136 & 221 & 1132 & 0 & 446 & 466 & 220 \\
\hline Goiás & 3452 & 1 & 956 & 1706 & 789 & 2889 & 1 & 895 & 1212 & 781 \\
\hline Distrito Federal & 838 & 1 & 526 & 0 & 311 & 762 & 1 & 452 & 0 & 309 \\
\hline
\end{tabular}

Fonte: IBGE. IB de G e E (2013) [24].

Notas: 1.0 mesmo estabelecimento pode oferecer mais de uma etapa/modalidade de ensino.

2. Estabelecimentos em atividade.

(1) Inclusive os dados da área rural.

Legenda:

Rio Grande do N: Rio Grande do Norte

Rio Grande do S: Rio Grande do Sul

Mato Grosso do S: Mato Grosso do Sul

Fed: Federal

Est: Estadual

Mun: Municipal

Priv: Privada 


\section{Anexo B: Termo de Consentimento}

Filho(a):

Mãe ou responsável:

Grau de parentesco do responsável: ( ) Mãe （ ) Outro-Quem?

Escola:

Município:

\section{Estudo da Saúde do Escolar Brasileiro}

Estamos convidando você a participar de uma pesquisa sobre a saúde dos estudantes brasileiros. Essa é uma pesquisa coordenada por professores da Universidade Federal de São Paulo, da Universidade Presbiteriana Mackenzie, da Universidade Federal do Rio Grande do Sul e da Universidade de São Paulo, com o apoio da Secretaria de Educação do seu município. Na sua cidade, 500 famílias estão sendo convidadas a participar dessa pesquisa. Com a sua participação, você vai nos ajudar a conhecer melhor a saúde das crianças e adolescentes de nosso país e com isso, procurar melhorar a assistência a eles.

Se você concordar em participar dessa pesquisa, será convidado(a) a responder perguntas sobre a saúde de seu filho(a) e de sua família. Todas as suas respostas serão mantidas em sigilo. Também precisamos de sua autorização para que seu filho(a) possa participar de uma avaliação quanto ao desenvolvimento e aprendizado escolar. Sua entrevista e a avaliação de seu filho(a) serão feitas ao mesmo tempo, em salas separadas e com duração de uma hora e meia. Mesmo concordando em participar, você poderá mudar de idéia e desistir da pesquisa a qualquer momento, sem nenhum problema para o atendimento de seu filho(a) na escola ou nos serviços de saúde.

Não haverá despesas pessoais para participar dessa pesquisa. Como retribuição a sua participação, forneceremos vale-transporte a você e a seu filho(a), além de um vale-compras no valor de $\mathrm{R} \$ 20,00$. É importante dizer que quando os resultados da pesquisa forem divulgados, a identidade dos participantes não será revelada.

Em qualquer etapa desse estudo, você poderá telefonar para os responsáveis pela pesquisa para tirar dúvidas. A Dra. Cristiane Silvestre de Paula, coordenadora geral da pesquisa, pode ser encontrada na Universidade Federal de São Paulo, na Rua Borges Lagoa, 570, tel. (11) $5572-7018$, ou deixar recado no tel. (11) 3069-7594. Caso não consiga nenhum desses números, o contato poderá também ser feito A COBRAR no número de celular (11)7837-5383. Se você tiver alguma dúvida sobre a ética da pesquisa, poderá entrar em contato com o Comitê de Ética em Pesquisa da Universidade de São Paulo (CAPPESQ) na Rua Dr. Ouvídio Pires 
de Campos, 255 - 50 andar

CEP: 05403-010 - Cerqueira César - São Paulo - SP ou através dos telefones (11) 3069-6431 ou (11) 30697322.

\section{Termo de Consentimento}

Eu, abaixo assinado(a), estou suficientemente esclarecido(a) sobre os objetivos da pesquisa e concordo em responder perguntas sobre a saúde de meu filho(a).

Também aceito que a equipe de pesquisa entre em contato comigo no futuro. Para que possam me encontrar, informo o nome, telefone e endereço das seguintes pessoas que me conhecem bem:

Nome:

\section{Endereço:}

Telefone:

Nome:

Endereço:

Telefone:

Nome:

Endereço:

Telefone:

Sei que mesmo que eu concorde em participar da entrevista, eu poderei mudar de idéia a qualquer momento e sair da pesquisa, sem nenhum problema para mim ou para minha família.

Data

Assinatura da mãe, pai ou adulto responsável pela criança ou adolescente

Data

Assinatura do profissional, membro da equipe de pesquisa 


\section{Anexo C - Indivíduos com TEA: DSM-IV x DSM-5}

Tabela 7 - Crianças e adolescentes com TEA com comprometimento global: DSM-IV $\mathrm{x}$ DSM-5

\begin{tabular}{|c|c|c|c|c|}
\hline \multirow[b]{2}{*}{ Cidade } & \multicolumn{4}{|c|}{ DSM-5 } \\
\hline & DSM-IV & $\begin{array}{l}\text { Sem dificuldade } \\
\text { de aprendizagem }\end{array}$ & $\begin{array}{l}\text { Dificuldade de } \\
\text { aprendizagem }\end{array}$ & Total \\
\hline \multirow[t]{3}{*}{ Caete-MG } & Sem Dificuldade & 419 & 12 & 431 \\
\hline & Com Dificuldade & 5 & 4 & 9 \\
\hline & & 424 & 16 & 440 \\
\hline \multirow[t]{3}{*}{ Goianira-GO } & Sem Dificuldade & 394 & 18 & 412 \\
\hline & Com Dificuldade & 9 & 4 & 13 \\
\hline & & 403 & 22 & 425 \\
\hline \multirow[t]{3}{*}{ Itaitinga-CE } & Sem Dificuldade & 354 & 19 & 373 \\
\hline & Com Dificuldade & 8 & 12 & 20 \\
\hline & & 362 & 31 & 393 \\
\hline \multirow[t]{3}{*}{ Rio Preto da Eva-AM } & Sem Dificuldade & 301 & 44 & 345 \\
\hline & Com Dificuldade & 5 & 10 & 15 \\
\hline & & 306 & 54 & 360 \\
\hline
\end{tabular}

Tabela 8 - Crianças e adolescentes com TEA com comprometimento na escrita: DSMIV x DSM-5

\begin{tabular}{|c|c|c|c|c|}
\hline \multirow[b]{2}{*}{ Cidade } & \multirow[b]{2}{*}{ DSM-IV } & \multicolumn{2}{|c|}{ DSM-5 } & \multirow[b]{2}{*}{ Total } \\
\hline & & $\begin{array}{l}\text { Sem dificuldade } \\
\text { de aprendizagem }\end{array}$ & $\begin{array}{l}\text { Dificuldade de } \\
\text { aprendizagem }\end{array}$ & \\
\hline \multirow[t]{3}{*}{ Caete-MG } & Sem Dificuldade & 427 & 8 & 435 \\
\hline & Com Dificuldade & 5 & 0 & 5 \\
\hline & & 432 & 8 & 440 \\
\hline \multirow[t]{3}{*}{ Goianira-GO } & Sem Dificuldade & 403 & 8 & 411 \\
\hline & Com Dificuldade & 12 & 2 & 14 \\
\hline & & 415 & 10 & 425 \\
\hline
\end{tabular}




\begin{tabular}{lrrrr} 
Itaitinga-CE & Sem Dificuldade & $\mathbf{3 5 5}$ & 23 & 378 \\
& Com Dificuldade & 10 & $\mathbf{5}$ & 15 \\
& & 365 & 28 & 393 \\
\multirow{3}{*}{ Rio Preto da Eva-AM } & & & \\
& & $\mathbf{3 1 2}$ & 38 & 350 \\
& Sem Dificuldade & 7 & 3 & 10 \\
& Com Dificuldade & 319 & 41 & 360 \\
\hline
\end{tabular}

Tabela 9 - Crianças e adolescentes com TEA com comprometimento na aritmética: DSM-IV x DSM-5

\begin{tabular}{|c|c|c|c|c|}
\hline \multirow[b]{2}{*}{ Cidade } & \multirow[b]{2}{*}{ DSM-IV } & \multicolumn{2}{|c|}{ DSM-5 } & \multirow[b]{2}{*}{ Total } \\
\hline & & $\begin{array}{l}\text { Sem dificuldade } \\
\text { de aprendizagem }\end{array}$ & $\begin{array}{l}\text { Dificuldade de } \\
\text { aprendizagem }\end{array}$ & \\
\hline \multirow[t]{3}{*}{ Caete-MG } & Sem Dificuldade & 409 & 18 & 427 \\
\hline & Com Dificuldade & 11 & 2 & 13 \\
\hline & & 420 & 20 & 440 \\
\hline \multirow[t]{3}{*}{ Goianira-GO } & Sem Dificuldade & 385 & 26 & 411 \\
\hline & Com Dificuldade & 10 & 4 & 14 \\
\hline & & 395 & 30 & 425 \\
\hline \multirow[t]{3}{*}{ Itaitinga-CE } & Sem Dificuldade & 361 & 14 & 375 \\
\hline & Com Dificuldade & 14 & 4 & 18 \\
\hline & & 375 & 18 & 393 \\
\hline \multirow[t]{3}{*}{ Rio Preto da Eva-AM } & Sem Dificuldade & 320 & 25 & 345 \\
\hline & Com Dificuldade & 11 & 4 & 15 \\
\hline & & 331 & 29 & 360 \\
\hline
\end{tabular}


Tabela 10 - Crianças e adolescentes com TEA com comprometimento na leitura: DSMIV $\times$ DSM-5

\begin{tabular}{|c|c|c|c|c|}
\hline \multirow[b]{2}{*}{ Cidade } & \multicolumn{4}{|c|}{ DSM-5 } \\
\hline & DSM-IV & $\begin{array}{l}\text { Sem dificuldade } \\
\text { de aprendizagem }\end{array}$ & $\begin{array}{l}\text { Dificuldade de } \\
\text { aprendizagem }\end{array}$ & Total \\
\hline \multirow[t]{3}{*}{ Caete-MG } & Sem Dificuldade & 421 & 10 & 431 \\
\hline & Com Dificuldade & 5 & 4 & 9 \\
\hline & & 426 & 14 & 440 \\
\hline \multirow[t]{3}{*}{ Goianira-GO } & Sem Dificuldade & 389 & 19 & 408 \\
\hline & Com Dificuldade & 10 & 7 & 17 \\
\hline & & 399 & 26 & 425 \\
\hline \multirow[t]{3}{*}{ Itaitinga-CE } & Sem Dificuldade & 351 & 17 & 368 \\
\hline & Com Dificuldade & 11 & 14 & 25 \\
\hline & & 362 & 31 & 393 \\
\hline \multirow[t]{3}{*}{ Rio Preto da Eva-AM } & Sem Dificuldade & 306 & 35 & 341 \\
\hline & Com Dificuldade & 4 & 15 & 19 \\
\hline & & 310 & 50 & 360 \\
\hline
\end{tabular}

\section{Anexo D: Tabela complementar de QI: perfil por cidade}

Tabela 11 - Média e desvio-padrão do QI por cidade

\begin{tabular}{llll}
\multicolumn{4}{c}{ QI } \\
Cidade & N & D.P. & Média \\
\hline Caete-MG & 440 & 11,98422 & $\mathbf{9 6 , 2 3 0 0}$ \\
Goianira-GO & 425 & 11,84797 & 93,2800 \\
Itaitinga-CE & 393 & 12,58145 & 95,8900 \\
Rio Preto da Eva-AM & 360 & 11,04140 & $\mathbf{8 8 , 9 0 0 0}$ \\
Total & 1.618 & 12,21972 & 93,7400 \\
\hline
\end{tabular}




\section{Anexo E: Tabela TDE}

Tabela 12 - Média e desvio-padrão por ano escolar do TDE

\begin{tabular}{|c|c|c|c|c|c|c|c|c|}
\hline \multicolumn{10}{|c|}{ Tabela TDE } \\
\hline \multirow{2}{*}{ Ano escolar } & \multicolumn{2}{|c|}{ Total } & \multicolumn{2}{c|}{ Aritmética } & \multicolumn{2}{c|}{ Leitura } & \multicolumn{2}{c|}{ Escrita } \\
\cline { 2 - 10 } & Média & D.P. & Média & D.P. & Média & D.P. & Média & D.P. \\
\hline $2^{\circ}$ & 51,82 & 38,26 & 6,01 & 3,59 & 34,67 & 27,18 & 11,14 & 8,94 \\
\hline $3^{\circ}$ & 92,11 & 21,87 & 11,35 & 3,49 & 58,83 & 13,43 & 21,92 & 6,81 \\
\hline $4^{\circ}$ & 106,31 & 10,90 & 16,00 & 3,39 & 64,57 & 4,67 & 25,74 & 5,26 \\
\hline $5^{\circ}$ & 116,30 & 7,23 & 20,82 & 3,80 & 66,67 & 2,56 & 28,81 & 3,83 \\
\hline $6^{\circ}$ & 120,46 & 6,91 & 22,29 & 3,94 & 67,97 & 2,71 & 30,20 & 3,38 \\
\hline $7^{\circ}$ & 126,20 & 6,03 & 25,67 & 3,85 & 68,72 & 1,82 & 31,81 & 3,06 \\
\hline
\end{tabular}

Fonte: Stein LM (1994) TDE: Teste de Desempenho Escolar - Manual para aplicação e interpretação [56]. 
Anexo F: Questionário sócio-econômico e de fatores de risco e proteção

\section{IDENTIFICAÇÃO}

Cidade Aluno

Nome do informante:

Nome completo da $\mathrm{Cl}$ :
Data: 1 1

Escola: ( ) urbana ( ) rural Informante é mãe da Cl: （） SIM （）NÃO Entrevistador:

\section{QUESTIONÁRIO INICIAL DE IDENTIFICAÇÃO, FATORES DE RISCO E PROTEÇÃO QUESTIONÁRIO PARA MÃE/SUBSTITUTA}

ENTREVISTADOR: $\mathrm{CI}$ = criança/adolescente índice; $\mathrm{MI}$ = Mulher índice; $\mathrm{MC}$ = marido ou companheiro da mãe

\section{Seção A. Identificacão familiar}

\section{SE MÃE BIOLÓGICA OU ADOTIVA FOR A INFORMANTE:}

A1. Qual seu nome completo:

A2. Qual sua idade: anos completos

A3. Qual a sua escolaridade?

Até que série você estudou (séries completas)? (Se não tiver completado nenhuma série, codifique 00)

I___ I anos

A4. O/A $<$ NOME DA CI> é seu filho(a) de sangue?

1 ( ) $\operatorname{Sim}$

2 ( ) Não $\rightarrow$ A4a Ele (a) é seu filho (a) como?

A5. Quantas pessoas moram na sua casa (situação atual): adultos (incluindo $M I$ ) e crianças/adolescentes $(<$ de 18 anos, incluindo $C I)$.

A6. Quantos irmãos(ãs) o/a $<N O M E D A C I>$ tem? (considerar meio-irmão se mencionado espontaneamente)

$\rightarrow$ A6a. Suas idades são: ( se não tiver irmãos, codifique 00)

A7. Qual sua situação conjugal (últimos 12 meses):

1 ( ) casada ou morando junto (marido residente)

2 ( ) casada ou morando junto (marido não residente nos últimos 12 meses)

3 ( ) solteira, nunca esteve casada

4 ( ) viúva

5 ( ) separada ou divorciada (a no mínimo 13 meses)

6 ( ) Outros (descreva)

$\rightarrow($ SE MI CASADA/MORANDO JUNTO RESPONDER ABAIXO, SE SOLTEIRA OU SEPARADA, IR PARA A15, pg 3$)$

A8. Qual o nome do seu M/C:

A9. Qual a idade do seu M/C: anos completos (NÃO SEI codifique 77).

A10. Qual a escolaridade do M/C?

Até que série ele estudou (séries completas)? (Se não tiver completado nenhuma série, codifique 00) I___ I anos (NÃO SEI codifique 77)

A11. Há quanto tempo moram/moraram juntos? /____ / anos completos (SE MENOS QUE UM ANO, CODIFIQUE OO) 
A12. O M/C está trabalhando atualmente (trabalho remunerado)?

2 ( ) Não

1 ( ) Sim (e mora com a MI) $\rightarrow$ A12a. Ele é assalariado ou recebe por dia/por trabalho? (NÃO LEIA A LISTA - RESPOSTA ESPONTÂNEA)

1 ( ) Assalariado $\rightarrow \quad$ A12b. 11( ) com registro 12( ) sem registro

2 ( ) Free lance/bico/autônomo/trabalha por conta (sem curso superior)

3 ( ) Profissional liberal (com curso superior)

4 ( ) Aposentado

5 ( ) Outros (descreva:

77 ( ) Não sei

3 ( ) Sim (mas ñão mora com a MI) $\rightarrow$ A12c. Ele é assalariado ou recebe trabalho? (NÃO LEIA A LISTA - RESPOSTA ESPONTÂNEA)

1 ( ) Assalariado $\rightarrow$ A12d. 11( ) com registro 12( ) sem registro

2 ( ) Free lance/bico/autônomo/trabalha por conta (sem curso superior)

3 ( ) Profissional liberal (com curso superior)

4 ( ) Aposentado

5 ( ) Outros (descreva:

77 ( ) Não sei

A13. E você, trabalhou nos últimos 30 dias (qualquer atividade remunerada)?

1 ( ) Sim $\rightarrow$ A13.a Quanto ganhou no último mês? reais

2 ( ) Não

A14. O M/C é o pai biológico/de sangue da CI?

1 ( ) $\mathrm{Sim} \rightarrow$ (IR PARA SEÇAO B, página 6)

2 ( ) Não $\rightarrow$ A14a. Com que freqüência o pai biológico/de sangue se encontra com <NOME DA CI>:

1 ( ) pelo menos uma vez por semana

2 ( ) a cada 15 dias

3 ( ) 1 vez por mês

4 ( ) menos de uma vez por mês

9 ( ) não se aplica; Descreva:

$\rightarrow$ A114b. Qual a escolaridade do pai biológico/de sangue da CI?

Até que série ele estudou (séries completas)? (Se não tiver completado nenhuma série, codifique 00)

I___ I anos (NÃO SEI codifique 77)

$\rightarrow$ A14c. O pai biológico/de sangue está trabalhando atualmente (trabalho remunerado)?

9 ( ) Não se aplica

77 ( ) Não sei

2 ( ) Não

1 ( ) Sim $\rightarrow$ A14d. Ele é assalariado ou recebe por dia/por trabalho?

(NÃO LEIA A LISTA - RESPOSTA ESPONTÂNEA)

1 ( ) Assalariado $\rightarrow \quad$ A14e. 11( ) com registro 12( ) sem registro

2 ( ) Free lance/bico/autônomo/trabalha por conta (sem curso superior)

3 ( ) Profissional liberal (com curso superior)

4 ( ) Aposentado

5 ( ) Outros (descreva:

77 ( ) Não sei

$\rightarrow$ A14f. Ele paga algum tipo de pensão ou contribui com os gastos da CI?

2 ( ) Não

1 ( ) Sim 


\section{- IR PARA SEÇAO B, PÁGINA 6 -}

$\rightarrow(\underline{\text { SE MI SOLTEIRA OU SEPARADA, RESPONDER ABAIXO }})$

A15. Com que frequiência o pai biológico/de sangue se encontra com $<N O M E D A C I>$ :

$$
\begin{aligned}
& 1 \text { ( ) pelo menos uma vez por semana } \\
& 2 \text { ( ) a cada } 15 \text { dias } \\
& 3 \text { ( ) } 1 \text { vez por mês } \\
& 4 \text { ( ) menos de uma vez por mês } \\
& 9 \text { ( ) não se aplica; Descreva: }
\end{aligned}
$$

A16. Qual a escolaridade do pai biológico/de sangue da CI?

Até que série ele estudou (séries completas)? (Se não tiver completado nenhuma série, codifique 00) I____ anos (NÃO SEI codifique 77)

A17. O pai biológico/de sangue está trabalhando atualmente (trabalho remunerado)?

9 ( ) Não se aplica

77 ( ) Não sei

2 ( ) Não

1 ( ) Sim $\rightarrow$ A17a. Ele é assalariado ou recebe por dia/por trabalho? (NÃO LEIA A LISTA - RESPOSTA ESPONTÂNEA)
1 ( ) Assalariado $\rightarrow \quad$ A17b. 11( ) com registro 12( ) sem registro
2 ( ) Free lance/bico/autônomo/trabalha por conta (sem curso superior)
3 ( ) Profissional liberal (com curso superior)
4 ( ) Aposentado
5 ( ) Outros (descreva:
77 ( ) Não sei

A18. Ele paga algum tipo de pensão ou contribui com os gastos da CI?

$$
\begin{array}{ll}
2 \text { ( ) Não } \\
1 \text { ( ) Sim }
\end{array}
$$

\section{- IR PARA SEÇAO B, PÁGINA 6 -}




\section{SE MÃE NÃ $O$ FOR A INFORMANTE}

AB1. Qual seu nome completo:

AB2. Qual o sexo do(a) informante: （ ） 1. Feminino （）2. Masculino

AB3. A mãe do(a) <NOME DA $C I>$ mora na casa com vocês?

1 ( ) $\operatorname{Sim}$

2 ( ) Não $\rightarrow$ AB3.a. Por qual motivo?

1 ( ) faleceu

2 ( ) mudou-se. Motivo:

3 ( ) está presa

4 ( ) Outros (descreva)

AB4. Há quanto tempo você é responsável por <NOME DA CI>?(Se menos de um ano, codifique 00)

I_l_ I anos

AB5. Com que freqüência o pai biológico/de sangue se encontra com <NOME DA CI>:
1 ( ) pelo menos uma vez por semana
2 ( ) a cada 15 dias
3 ( ) 1 vez por mês
4 ( ) menos de uma vez por mês
9 ( ) não se aplica; Descreva:

AB6. Qual a escolaridade do pai biológico/de sangue da CI?

Até que série ele estudou (séries completas)? (Se não tiver completado nenhuma série, codifique 00)

I___ I anos (NÃO SEI codifique 77)

AB7. O pai biológico/de sangue está trabalhando atualmente (trabalho remunerado)?

9 ( ) Não se aplica

77 ( ) Não sei

2 ( ) Não

1 ( ) Sim $\rightarrow$ AB7.a. Ele é assalariado ou recebe por dia/por trabalho?

(NÃO LEIA A LISTA - RESPOSTA ESPONTÂNEA)

1 ( ) Assalariado $\rightarrow \quad$ AB7.b. 11( ) com registro 12( ) sem registro

2 ( ) Free lance/bico/autônomo/trabalha por conta (sem curso superior)

3 ( ) Profissional liberal (com curso superior)

4 ( ) Aposentado

5 ( ) Outros (descreva:

77 ( ) Não sei

AB8. Ele paga algum tipo de pensão ou contribui com os gastos da CI?

$$
\begin{aligned}
& 2 \text { ( ) Não } \\
& 1 \text { ( ) Sim }
\end{aligned}
$$

AB9. Agora vou fazer várias perguntas sobre você $(M I)$. Qual sua idade: anos completos

AB10. Até que série você estudou (séries completas)? (Se não tiver completado nenhuma série, codifique 00) I___ anos

AB11. Qual sua relação com <NOME DA CI>?

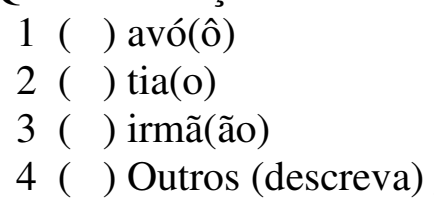


AB12. Você está trabalhando atualmente (trabalho remunerado)?

1 ( ) Sim $\rightarrow$ A12.a Quanto ganhou no último mês? reais

2 ( ) Não

AB13. Qual sua situação conjugal:

1 ( ) casada ou morando junto (marido residente)

2 ( ) casada ou morando junto (marido não residente nos últimos 12 meses)

3 ( ) solteira, nunca esteve casada

4 ( ) viúva

5 ( ) separada ou divorciada (a no mínimo 13 meses)

6 ( ) Outros (descreva)

$\rightarrow(\underline{\text { SE MI CASADA/MORANDO JUNTO RESPONDER ABAIXO, SE SOLTEIRA/SEPARADA, IR PARA SECAO B, pg } 6})$

AB14. Qual a idade do seu M/C: anos completos

AB15. Qual a escolaridade do seu M/C? Até que série ele estudou (séries completas)?

(Se não tiver completado nenhuma série, codifique 00)

I_I_ I anos (NÃO SEI codifique 77)

AB16. O M/C está trabalhando atualmente (trabalho remunerado)?

2 ( ) Não

1 ( ) Sim $\rightarrow$ AB16a. Ele é assalariado ou recebe por dia/por trabalho?

(NÃO LEIA A LISTA - RESPOSTA ESPONTÂNEA)

1 ( ) Assalariado $\rightarrow$ AB16.b. 11( ) com registro 12( ) sem registro

2 ( ) Free lance/bico/autônomo/trabalha por conta (sem curso superior)

3 ( ) Profissional liberal (com curso superior)

4 ( ) Aposentado

5 ( ) Outros (descreva:

77 ( ) Não sei 


\section{Seção B: Crianca Índice e bens de consumo da família}

Agora eu gostaria de perguntar um pouco sobre sua CASA. Você tem na sua casa:

ENTREVISTADOR: PREENCHER COM O QUE A PESSOA POSSUI EM CASA (CONSIDERAR ITENS QUEBRADOS HÁ MENOS DE 6 MESES); CONSIDERAR A QUANTIDADE DE ITENS DA PRIMEIRA LINHA DO QUADRO - EM NEGRITO

\begin{tabular}{|l|c|c|c|c|c|}
\hline \multicolumn{1}{|c|}{ QUADRO 1 (ABEP) } & Não & \multicolumn{5}{c|}{ Tem } \\
\cline { 3 - 6 } & Tem & $\mathbf{1}$ & $\mathbf{2}$ & $\mathbf{3}$ & $\mathbf{4}$ ou + \\
\hline Televisão em cores & 0 & 1 & 2 & 3 & 4 \\
\hline Rádio (qualquer aparelho no domicílio, exceto rádio do carro) & 0 & 1 & 2 & 3 & 4 \\
\hline Banheiro (com vaso sanitário e privativo do domić́lio) & 0 & 4 & 5 & 6 & 7 \\
\hline Automóvel (sem uso profissional) & 0 & 4 & 7 & 9 & 9 \\
\hline Empregada mensalista & 0 & 3 & 4 & 4 & 4 \\
\hline Máquina de lavar (excluir tanquinho) & 0 & 2 & 2 & 2 & 2 \\
\hline Videocassete e/ou DVD & 0 & 2 & 2 & 2 & 2 \\
\hline Geladeira & 0 & 4 & 4 & 4 & 4 \\
\hline Freezer (aparelho independente ou parte da geladeira duplex) & 0 & 2 & 2 & 2 & 2 \\
\hline BB.1 SOMA DE PONTOS & & & & \\
\hline
\end{tabular}

Quem é o chefe da família? Até que série o CHEFE DA FAMÍLIA estudou? (séries completas) anos (SE NÃO TIVER COMPLETADO NENHUMA SÉRIE, CODIFIQUE OO)

ENTREVISTADOR: SE O ENTREVISTADO TIVER OUTROS FILHOS, FAVOR ENFATIZAR NO DECORRER DA ENTREVISTA QUE AS QUESTÕES REFEREM-SE SOMENTE À CI

Agora eu gostaria de perguntar a você sobre o(a) $<N O M E D A C I>$ :

B1. Qual o sexo do(a) <NOME DA CI>: （） 1. Feminino ～～2. Masculino

B2. Qual a idade do(a) <NOME DA CI>: /______ _ _ anos completos (conferir com B3 e com quadro de identificação)

B3. Qual a data de nascimento do(a) $<$ NOME DA CI $>$ :________ (

B4. Você teve alguma complicação de saúde na gravidez do(a) <NOME DA CI>:

( ) 2. Não ( ) 1. Sim $\rightarrow$ Descreva:

(Se MI não for mãe da CI, perguntar sobre a mãe; se NÃO SEI codifique 77).

B5. Você usou cigarro, álcool e/ou drogas na gravidez do(a) $<N O M E D A C I>$ :

( ) 2. Não ( ) 1. Sim $\rightarrow$ Descreva:

(Se MI não for mãe da CI, perguntar sobre a mãe; se NÃO SEI codifique 77).

B6. $\mathrm{O}(\mathrm{a})<N O M E D A C I>$ teve alguma complicação séria de saúde durante o $1^{\circ}$ ano de vida?

( ) 2. Não ( ) 1. Sim $\rightarrow$ Descreva:

(Se MI não for mãe da CI, perguntar se tem informações da CI nessa época; se NÃO SEI codifique 77).

B.7. $\mathrm{O}(\mathrm{a})<N O M E D A C I>$ já repetiu de ano alguma vez?

1 ( ) Sim $\rightarrow$ B.7a. Quantas vezes ele/ela repetiu de ano? /_/_/ vezes

2 ( ) Não 


\section{$\underline{\text { Ten Questions Screen }}$}

B8. Em comparação com outras crianças da mesma idade, o/a $<N O M E D A C I>$ teve algum atraso para sentar, ficar em pé, ou andar?

1 ( ) $\operatorname{Sim} \Rightarrow$ Descreva:

2 ( ) Não

B9. Em comparação com outras crianças, o/a $<$ NOME DA CI> tem alguma dificuldade em enxergar, seja durante o dia ou à noite?

2 ( ) Não

1 ( ) Sim $\rightarrow$ B9a. A dificuldade em enxergar do/a $<$ NOME DA CI> é corrigida com uso de óculos?

1 ( ) Sim

2 ( ) Não $\Rightarrow$ Descreva:

B10. O/A <NOME DA $C I>$ parece ter alguma dificuldade em escutar?

1 ( ) $\mathrm{Sim} \Rightarrow$ Descreva:

2 ( ) Não

B11. Quando você fala para o/a $<N O M E D A C I>$ fazer alguma coisa, ele(a) parece entender o que você está falando?

$1($ ) $\operatorname{Sim}$

2 ( ) Não $\Rightarrow$ Descreva:

B12. O/A <NOME DA $C I>$ tem alguma dificuldade em andar e/ou, mexer seus braços, ou tem fraqueza ou rigidez nos braços ou nas pernas?

1 ( ) $\mathrm{Sim} \Rightarrow$ Descreva:

2 ( ) Não

$\mathrm{B} 13 . \mathrm{O} / \mathrm{A}<$ NOME DA $C I>$ às vezes tem convulsões, se torna rígida(o), ou perde a consciência?

1 ( ) $\mathrm{Sim} \Rightarrow$ Descreva:

2 ( ) Não

B14. O/A <NOME DA $C I>$ aprende a fazer coisas como as outras crianças da mesma idade?

1 ( ) $\operatorname{Sim}$

2 ( ) Não $\Rightarrow$ Descreva:

B15. O/A $<N O M E D A C I>$ fala (ou seja, ele/a se faz entender com palavras; ele/a fala alguma palavra reconhecível)?

1 ( ) $\mathrm{Sim}$

2 ( ) Não $\Rightarrow$ Descreva:

B16. A fala do/a $<N O M E D A C I>$ é diferente de alguma maneira do normal (não clara o suficiente para ser entendida por outras pessoas além da família mais próxima)?

1 ( ) $\operatorname{Sim} \Rightarrow$ Descreva:

2 ( ) Não

B17. Em comparação com outras crianças da mesma idade, o/a $<N O M E D A C I>$ parece de alguma maneira ser atrasado(a), limitado(a), ou mais lento mentalmente?

1 ( ) $\operatorname{Sim} \Rightarrow$ Descreva:

2 ( ) Não 
Seção C: Saúde Mental da Mulher Índice (mãe ou principal cuidador da CI)

Agora eu gostaria de perguntar algumas coisas sobre a sua saúde

(ATENÇÃO: sintoma presente nos últimos 30 dias; EXCEÇÃO C17, C21 E C22 em qualquer momento da vida)

\begin{tabular}{|c|c|c|}
\hline Questões & Sim & Não \\
\hline C1. Tem dores de cabeca freqüentes? & 1 & 2 \\
\hline C.2. Tem falta de apetite? & 1 & 2 \\
\hline C.3. Dorme mal? & 1 & 2 \\
\hline C.4. Assusta-se com facilidade? & 1 & 2 \\
\hline C.5. Tem tremores na mão? & 1 & 2 \\
\hline C.6. Sente-se nervosa, tensa ou preocupada? & 1 & 2 \\
\hline C.7. Tem má digestão? & 1 & 2 \\
\hline C.8. Tem dificuldade de pensar com clareza? & 1 & 2 \\
\hline C.9. Tem se sentido triste ultimamente? & 1 & 2 \\
\hline C.10. Tem chorado mais do que de costume? & 1 & 2 \\
\hline C.11. Encontra dificuldades para realizar com satisfação suas atividades diárias? & 1 & 2 \\
\hline C.12. Tem dificuldades para tomar decisões? & 1 & 2 \\
\hline C.13. Tem dificuldades no servico (seu trabalho é penoso, lhe causa sofrimento)? & 1 & 2 \\
\hline C.14. É incapaz de desempenhar um papel útil em sua vida? & 1 & 2 \\
\hline C.15. Tem perdido o interesse pelas coisas? & 1 & 2 \\
\hline C.16. Você se sente uma pessoa inútil, sem préstimo? & 1 & 2 \\
\hline C.17. Tem tido a idéia de acabar com a vida? & 1 & 2 \\
\hline C.18. Sente-se cansada o tempo todo? & 1 & 2 \\
\hline C.19. Tem sensações desagradáveis no estômago? & 1 & 2 \\
\hline C.20. Se cansa com facilidade? & 1 & 2 \\
\hline C.21. Alguma vez você já pensou em se matar? & 1 & 2 \\
\hline C.22. Alguma vez você iá tentou se matar? & 1 & 2 \\
\hline
\end{tabular}




\section{Seção D. Família de Origem da MI}

Agora vamos falar um pouco sobre sua família e seu bairro.

D1.Você nasceu em <CIDADE ONDE ENTREVISTA ESTÁ SENDO REALIZADA>?

2 ( ) Não

$1($ ) Sim $\rightarrow$ Se sim - pular para E.1.

D1a. Porque você se mudou da cidade onde nasceu?

D1b. Sua vida é melhor aqui em <CIDADE ONDE ENTREVISTA ESTÁ SENDO REALIZADA> do que antes de vir para cá?

1 ( ) $\mathrm{Sim}$

2 ( ) Não

3 ( ) Outros. Descreva

\section{Seção E. Suporte social e qualidade do bairro onde vive}

E1. Quando você necessita de ajuda ou tem algum problema, pode contar com o apoio de:

E1. SUA FAMÍLIA?

1 ( ) Nunca

2 ( ) Às vezes (às vezes sim, às vezes não)

3 ( ) Sempre

E1a. VIZINHOS E/OU AMIGOS?

1 ( ) Nunca

2 ( ) Às vezes (às vezes sim, às vezes não)

3 ( ) Sempre

E1b. COLEGAS DE TRABALHO OU ESCOLA?

1 ( ) Nunca

2 ( ) Às vezes (às vezes sim, às vezes não)

3 ( ) Sempre

9 ( ) Não se aplica, pois MI não trabalha fora nem estuda

E2. O bairro onde vocês moram é perigoso?
1 ( ) Não
2 ( ) Um pouco
3 ( ) Muito

E3. O/A <NOME DA CI $>$ já foi assaltado(a) ou estava com uma pessoa que foi assaltada?

2 ( ) Não

$1($ ) Sim $\rightarrow$ E3a. O assalto foi com arma de fogo 1 ( ) Sim

2 ( ) Não

E4. O/A <NOME DA CI> já viu alguém ser assaltado (excluir situação acima)?

2 ( ) Não

1 ( ) Sim $\rightarrow$ E4a. Com arma de fogo 1 ( ) Sim

2 ( ) Não

E5. O/A <NOME DA CI> já viu alguém ser assassinado?

1 ( ) $\operatorname{Sim}$

2 ( ) Não

E6. O/A <NOME DA CI> já presenciou um tiroteio?

1 ( ) $\mathrm{Sim}$

2 ( ) Não 


\section{Seção F. Auto-estima e características de personalidade da CI}

Vamos voltar a falar agora sobre o/a $<N O M E D A C I>$. Quero que me diga o que acha das frases abaixo:

F1. O/a <NOME DA CI $>$ se sente capaz de fazer coisas tão bem quanto a maioria das crianças da idade dele(a).

\begin{tabular}{|c|c|c|c|c|}
\hline & Concordo totalmente & Concordo & Discordo & Discordo totalmente \\
\hline PONTOS & 1 & 2 & 3 & 4 \\
\hline
\end{tabular}

F2. De forma geral, o/a $<N O M E D A C I>$ está satisfeito(a) consigo mesmo(a).

\begin{tabular}{|c|c|c|c|c|}
\hline & Concordo totalmente & Concordo & Discordo & Discordo totalmente \\
\hline PONTOS & 1 & 2 & 3 & 4 \\
\hline
\end{tabular}

F3. O/a $<$ NOME DA $C I>$ acha que tem diversas boas qualidades.

\begin{tabular}{|c|c|c|c|c|}
\hline & Concordo totalmente & Concordo & Discordo & Discordo totalmente \\
\hline PONTOS & 1 & 2 & 3 & 4 \\
\hline
\end{tabular}

F4. O/A <NOME DA CI> tem uma atitude positiva em relação a si mesmo:

1 ( ) Sempre

2 ( ) As vezes

3 ( ) Raramente/nunca

F5. O/A <NOME DA CI> se acha decidido:

1 ( ) Sim

2 ( ) Não

F6. O/A <NOME DA $C I>$ insiste em coisas que ele(a) não pode fazer nada para mudar:

1 ( ) Sempre

2 ( ) As vezes

3 ( ) Raramente/nunca

F7. O/A <NOME DA CI> consegue mudar seu comportamento para se adaptar a uma situação nova:

1 ( ) Sempre

2 ( ) As vezes

3 ( ) Raramente/nunca

F8. O/A <NOME DA $C I>$ desiste facilmente quando as coisas saem errado:

1 ( ) $\mathrm{Sim}$

2 ( ) Não

F9. O/A <NOME DA CI> geralmente consegue lidar com os problemas dele/dela:

1 ( ) $\mathrm{Sim}$

2 ( ) Não

F10. Quando o/a <NOME DA CI> está numa situação difícil, normalmente acha uma saída/solução:

1 ( ) $\operatorname{Sim}$

2 ( ) Não

F11. O/A $<N O M E D A C I>$ é freqüentemente procurado por colegas/amigos para ajudar a resolver brigas ou conflitos:
1 ( ) Sim
2 ( ) Não 


\section{Seção G. Ambiente familiar, comunitário e supervisão da CI}

G1 Você geralmente sabe onde o/a <NOME DA CI> está?

1 ( ) $\operatorname{Sim}$

2 ( ) Não

G2 Você geralmente sabe o que o/a $<N O M E D A C I>$ está fazendo?

1 ( ) $\operatorname{Sim}$

2 ( ) Não

G3. Na sua casa existem regras claras sobre o que o/a $<N O M E D A C I>$ pode e não pode fazer?

1 ( ) Sim

2 ( ) Não

G4. Você sabe o que o/a $<N O M E D A C I>$ gosta e o que ele(a) não gosta?

1 ( ) $\operatorname{Sim}$

2 ( ) Não

G5. Na sua família as pessoas são aceitas do jeito que elas são?

1 ( ) Sim

2 ( ) Não

G6. Você acha que o/a <NOME DA CI> se sente bem quando está com a família?

1 ( ) Sim

2 ( ) Não

G7. Você costuma conversar com o/a $<N O M E D A C I>$ sobre coisas que interessam a ele(a)?

1 ( ) $\operatorname{Sim}$

2 ( ) Não

G8. Você tem discussões freqüentes com o/a $<N O M E D A C I>$ que envolvem gritos e berros?

1 ( ) $\operatorname{Sim}$

2 ( ) Não

G9. Você acha que você e seu M/C brigam tanto a ponto de tumultuar o ambiente familiar?

1 ( ) Sim

2 ( ) Não

9 ( ) Não se aplica (não tem/teve M/C nos últimos 12 meses - confirmar A7 ou AB13)

G10. Na sua família acontecem brigas com agressão física?

2 ( ) Não

1 ( ) Sim $\rightarrow$ G10a. Acontecem agressões físicas entre os pais/responsáveis de CI?

1 ( ) Sim

2 ( ) Não

9 ( ) Não se aplica (não tem M/C nos últimos 12 meses)

(confirmar A7 ou AB13)

$\rightarrow$ G10b. Acontecem agressões físicas entre você e/ou seu M/C e a CI?

1 ( ) Sim (considerar agressões em qualquer momento da vida da CI)

2 ( ) Não

G11. Você ou <nome do M/C nos últimos 12 meses elou pai biológico da CI> bateu na bunda com algum objeto como vara, vassoura, pedaço de pau ou cinto no/a $<N O M E D A C I>$ de ... para cá (últimos 12 meses)?

1 ( ) nunca

2 ( ) uma ou duas vezes

3 ( ) três vezes ou mais 
G12. Você ou <nome do M/C nos últimos 12 meses elou pai biológico da CI> bateu, espancou ou empurrou com força suficiente para causar ferimentos no/a $<$ NOME DA CI> de ... para cá (últimos 12 meses)?
1 ( ) nunca
2 ( ) uma ou duas vezes
3 ( ) três vezes ou mais

\section{Seção H. Envolvimento da criança em atividades pró-sociais}

H1. O/A <NOME DA CI> participa de alguma atividade extra-escolar com alguém tomando conta: professor, monitor, treinador ou educador? (excluir atividades obrigatórias da escola)?
1 ( ) Sim. Descreva:
2 ( ) Não

H2. O/A <NOME DA $C I>$ tem alguma religião?

2 ( ) Não

1 ( ) Sim $\rightarrow$ H2a. Com que freqüência vai à missa, culto ou a alguma atividade religiosa (usar o termo mencionado pelo informante)?

1 ( ) pelo menos uma vez/semana 2( ) a cada 15 dias $3($ ) 1 vez/mês $4($ ) menos de uma vez/mês

\section{Seção I. Perguntas sobre o uso de servicos de saúde mental}

I.1. Nos últimos 12 meses, o/a <NOME DA CI $>$ foi atendido por psiquiatra por problemas emocionais, de comportamento ou problemas com álcool ou drogas?

2 ( ) Não
1 ( ) Sim $\rightarrow$ Descreva:

I.2. Nos últimos 12 meses, o/a <NOME DA CI $>$ foi atendido por neurologista por problemas emocionais, de comportamento ou problemas com álcool ou drogas?

2 ( ) Não

1 ( ) Sim $\rightarrow$ Descreva:

I.3. Nos últimos 12 meses, o/a <NOME DA CI $>$ foi atendido por psicóloga(o) por problemas emocionais, de comportamento ou problemas com álcool ou drogas?

2 ( ) Não
1 ( ) Sim $\rightarrow$ Descreva:

I.4. Nos últimos 12 meses, o/a <NOME DA CI $>$ foi atendido por algum outro profissional de saúde por problemas emocionais, de comportamento ou problemas com álcool ou drogas?

2 ( ) Não

1 ( ) Sim $\rightarrow$ Descreva:

I.5. Nos últimos 12 meses, o/a <NOME DA CI > recebeu acompanhamento individualizado em uma sala de aula regular ou freqüentou a sala de recursos ou sala especial na escola onde estuda?

2 ( ) Não

1 ( ) Sim $\rightarrow$ Descreva:

SE SIM EM ALGUM DOS ITENS DA SEÇAO I ACIMA (I.1 A I.5), PERGUNTE ABAIXO, SENÃO ENCERRE A ENTREVISTA e PREENCHA QUADROS DA PÁGINA 14. 
I.6. Nos últimos 12 meses, o/a <NOME DA CI> recebeu algum diagnóstico, ou seja, lhe disseram o nome do problema ou problemas que ele(a) tem ou teve para ter recebido o atendimento citado acima?

2 ( ) Não

1 ( ) Sim $\rightarrow$ I.6a. Descreva diagnóstico:

I.6b. Seu filho toma/tomou remédio para este problema?

\section{2 ( ) Não}

$1($ ) Sim $\rightarrow$ I.6c. Qual nome do remédio (anote todas as informações que conseguir):

I.7. Esses atendimentos (repetir atendimento referido entre I.1 e I.5) são/eram realizados com que freqüência? Assinalar com um " $X$ " no quadro abaixo, indicando a frequiência dos tratamentos feitos e/ou ainda em andamento.

(Lembrar que estamos falando dos tratamentos dos últimos 12 meses).

\begin{tabular}{|c|c|c|c|c|c|c|c|}
\hline Tipo de tratamento & $\begin{array}{c}(1) \\
\text { Diariam }\end{array}$ & $\begin{array}{c}(2) \\
2 \text { a } 3 \\
\text { vezes/ } \\
\text { semana }\end{array}$ & $\begin{array}{c}(3) \\
1 \mathrm{vez} / \\
\text { semana }\end{array}$ & $\begin{array}{c}(4) \\
\text { A cada } 15 \\
\text { dias }\end{array}$ & $\begin{array}{c}(5) \\
1 \\
\text { vez/mês }\end{array}$ & $\begin{array}{c}\text { (6) } \\
\text { Menos } \\
\text { de } 1 \\
\text { vez/mês }\end{array}$ & $\begin{array}{c}(8) \\
\text { Outros } \\
\text { (descreva) }\end{array}$ \\
\hline (a) Psiquiatra & & & & & & & \\
\hline (b) Neurologista & & & & & & & \\
\hline (c) Psicóloga(o) & & & & & & & \\
\hline $\begin{array}{l}\text { (d) Outro profissional de saúde } \\
\text { Qual: }\end{array}$ & & & & & & & \\
\hline $\begin{array}{l}\text { (e) Outro profissional de saúde } \\
\text { Qual: }\end{array}$ & & & & & & & \\
\hline $\begin{array}{l}\text { (f) Acompanhamento } \\
\text { individualizado ou sala de } \\
\text { recursos na escola }\end{array}$ & & & & & & & \\
\hline
\end{tabular}

I.8. Esses atendimentos (repetir o atendimento mencionado entre I.1 e I.5) duram/duraram quanto tempo?

Assinalar com um " $X$ " no quadro abaixo, indicando a duração dos tratamentos feitos e/ou ainda em andamento (lembrar que estamos falando dos tratamentos dos últimos 12 meses).

\begin{tabular}{|l|c|c|c|c|c|c|c|}
\hline Tipo de tratamento & $\begin{array}{c}(1) \\
\text { Menos de } \\
1 \text { mês }\end{array}$ & $\begin{array}{c}\text { 1 a 3 } \\
\text { meses }\end{array}$ & $\begin{array}{c}\text { 4) } \\
\text { 6 meses }\end{array}$ & $\begin{array}{c}\text { Mais de } \\
6 \text { meses }\end{array}$ & $\begin{array}{c}\text { (8) } \\
\text { Outros } \\
\text { (descreva) }\end{array}$ & \multicolumn{2}{|c|}{ O tratamento } \\
Sim foi finalizado? \\
\hline (a) Psiquiatra & & & & & & & \\
\hline (b) Neurologista & & & & & & & \\
\hline (c) Psicóloga & & & & & & & \\
\hline $\begin{array}{l}\text { (d) Outro profissional de } \\
\text { saúde Qual: }\end{array}$ & & & & & & & \\
\hline $\begin{array}{l}\text { (e) Outro profissional de } \\
\text { saúde Qual: }\end{array}$ & & & & & & & \\
\hline $\begin{array}{l}\text { (f) Acompanhamento } \\
\text { individualizado ou sala } \\
\text { de recursos na escola }\end{array}$ & & & & & & & \\
\hline
\end{tabular}


I.9. Você acha que ele(a) teve melhora com algum dos tratamentos citados acima?

$$
\begin{array}{r}
2 \text { ( ) Não } \\
1 \text { ( ) Sim } \rightarrow \text { Se sim - I.9a. 1 ( ) Um pouco } \\
\end{array}
$$

Descreva o tipo de tratamento e a melhora observada:

I.10. Há mais de 12 meses atrás, o/a <NOME DA CI> já recebeu algum atendimento/tratamento de psiquiatra, psicólogo, neurologista, ou outro profissional da saúde por problemas emocionais, de comportamento ou problemas com álcool ou drogas?

2 ( ) Não

1 ( ) Sim $\rightarrow$ Se sim, I.10.a. Há quanto tempo atrás? anos atrás

\section{FIM DA ENTREVISTA}

\section{ENTREVISTADOR: PEÇA licença à MI por alguns minutos e PREENCHA AGORA ABAIXO}

\section{QUADRO 2 (BB.2)}

\begin{tabular}{|l|c|c|}
\hline Grau de Instrução do chefe de família (pg 6) & Última série que completou & Pontuação \\
\hline Analfabeto / Primário incompleto & Analfabeto até $3^{\mathrm{a}}$ série do fundamental & 0 \\
\hline Primário completo / Ginasial incompleto & $4^{\mathrm{a}}$ a $7^{\mathrm{a}}$ do fundamental & 1 \\
\hline Ginasial completo / Colegial incompleto & $8-10$ (Fundamental completo) & 2 \\
\hline Colegial completo / Superior incompleto & Médio completo & 4 \\
\hline Superior completo & Superior completo & 8 \\
\hline
\end{tabular}

\section{BB.3 - SOMA DE PONTOS =}

QUADRO 1 (BB.1 - página 6) + QUADRO 2 (BB.2 acima)

BB4. A soma de pontos corresponde à classe econômica: (ver Quadro 3 abaixo) 


\section{REFERÊNCIAS}

1. Alesi M, Rappo F, Pepi A (2012) Self-esteem at school and self-handicapping in childhood: comparison of groups with learning disabilities. Psychol Rep 111(3):95262

2. Al-Yagon M, Cavendish W, Cornoldi C, Fawcett AJ, Grünke M, Hung LY, Jiménez JE, Karande S, van Kraayenoord CE, Lucangeli D, Margalit M, Montague M, Sholapurwala R, Sideridis G, Tressoldi PE, Vio C (2013) The proposed changes for DSM-5 for SLD and ADHD: international perspectives - Australia, Germany, Greece, India, Israel, Italy, Spain, Taiwan, United Kingdom, and United States. J Learn Disabil 46(1):58-72

3. Altarac M, Saroha MA (2007). Life time prevalence of learning disability among U.S. children. Pediatrics 119 (Suppl): S77-S83

4. American Psychiatric Association (2000) Diagnostic and statistical manual of mental disorders $4^{\text {th }}$ edn (DSM-IV). APA, Washington, DC

6. American Psychiatric Association (2013) Diagnostic and statistical manual of mental disorders $5^{\text {th }}$ edn (DSM-5). APA, Washington, DC

6. American Psychiatric Association (2013) Specific Learning Disorder Fact Sheet. American Psychiatric Publishing

7. Associação Brasileira de Pesquisa de Mercado A (2007) Critério de classificação econômica Brasil. Available at: www.abep.org/novo/FileGenerate.ashx?id=250

8. Atlas do Desenvolvimento Humano (2013) based on 2010 census data. Available at: http://www.atlasbrasil.org.br/2013/

9. Biederman J, Newcorn J, Sprich S (1991) Comorbidity of attention deficit hyperactivity disorder with conduct, depressive, anxiety, and other disorders. Am J Psychiatry 148(5): 564-77 
10. Brasil HH, Bordin IA (2010) Convergent validity of K-SADS-PL by comparison with CBCL in a Portuguese speaking outpatient population. BMC Psychiatry 10:83

11. Bruckner TA, Scheffler RM, Shen G, Yoon J, Chisholm D, Morris J, Fulton BD, Dal Poz MR, Saxena S (2011) The mental health workforce gap in low- and middleincome countries: a needs-based approach. Bull World Health Organ 89(3):184-94

12. Butterworth B, Kovas $Y$ (2013) Understanding neurocognitive developmental disorders can improve education for all. Science 340 (6130): 300-5

13. Capellini SA, Coppede AC, Valle TR (2010) Fine motor function of school-aged children with dyslexia, learning disability and learning difficulties [Função motora fina de escolares com dislexia, distúrbio e dificuldades de aprendizagem]. PróFono Revista de Atualização Científica 22(3):201-8

14. Capozzi F, Casini MP, Romani M, De Gennaro L, Nicolais G, Solano L (2008) Psychiatric comorbidity in learning disorder: Analysis of family variables. Child Psychiatry \& Human Development 39(1):101-110

15. Del'Homme M, Kim TS, Loo SK, Yang MH, Smalley SL (2006) Familial association and frequency of learning disabilities in ADHD sibling pair families. J Abnorm Child Psychol 35(1):55-62

16. DuPaul GJ, Gormley MJ, Laracy SD (2013) Comorbidity of LD and ADHD: implications of DSM-5 for assessment and treatment. J Learn Disabil 43-51

17. DuPaul, GJ, \& Volpe, RJ (2009). ADHD and learning disabilities: Research findings and clinical implications. Current Attention Disorders Reports 1(4):152155

18. Fastenau PS, Jianzhao Shen, Dunn DW, Austin JK (2008) Academic underachievement among children with epilepsy: proportion Exceeding psychometric criteria for learning disability and associated risk factors. J Learn Disabil 41(3): 195-207 
19. Francis DJ, Fletcher JM, Stuebing KK, Lyon GR, Shaywitz BA., Shaywitz SE (2005) Psychometric approaches to the identification of LD: IQ and achievement scores are not sufficient. Journal of Learning Disabilities 38(2):98-108

20. Hale J, Alfonso V, Berninger V, Bracken B, Christo C, Clark E, Yalof J (2010) Critical issues in response-to-intervention, comprehensive evaluation, and specific learning disabilities identification and intervention: An expert white paper consensus. Learning Disability Quaterly 33(3):223-236

21. Haviou-Thomas ME (2008) Genetic ans environmental influences on early speech, language and literacy development. J Commun Disord 41(5): 397-408

22. House of Commons (2008) A Life Like Any Other? Human Rights of Adults with Learning Disabilities. London: The Stationery Office Limited

23. Huc-Chabrolle M, Barthez MA, Tripi G, Barthélémy C, Bonnet-Brilhault F (2010) Psychocognitive and psychiatric disorders associated with developmental dyslexia: A clinical and scientific issue. Encephale 36(2):172-9

24. IBGE. IB de G e E (2013) Cidades@. Disponível em:http://www.ibge.gov.br/cidadesat

25. IBGE. IB de G e E (2010) Séries históricas e estatísticas. Disponível em: http://seriesestatisticas.ibge.gov.br/series.. spx $? \mathrm{no}=10 \& \mathrm{op}=0 \& \mathrm{v} \operatorname{codigo}=\mathrm{CD} 97 \& \mathrm{t}=\mathrm{n}$ umero-municipios-censo-demografico-classes-tamanho

26. Kaufman J et al. (1996) Kiddie-Sads-Present and Lifetime Version (K-SADS-PL) Version 1.0.

[http://www.psychiatry.pitt.edu/sites/default/files/Documents/assessments/ksadspl.pdf]

27. Kaufman J, Birmaher B, Brent D, Rao U, Flynn C, Moreci P, Williamson D, Ryan N (1996) Schedule for Affective Disorders and Schizophrenia for School-Age Children-Present and Lifetime Version (K-SADS-PL): Initial Reliability and Validity Data. J. Am. Acad. Child Adolescent Psychiatry 36(7): 980-988 
28. Landerl K, Moll K (2010) Comorbidity of learning disorders: prevalence and familial transmission. J Child Psychol Psychiatry 51(3):287-94

29. Landis JR, Koch GG (1977). The measurement of observer agreement for categorical data. Biometrics; 33(1): 159-174

30. Lyon GR (1996) Learning Disabilities. The Future of Children 6(1):54-76

31. Lyon GR, Fletcher JM, Shaywitz SE, Shaywitz BA, Torgesen JK, Wood FB, Schulte A, Olson R (2001) Rethinking Learning Disabilities. In: C.E. Finn Jr., R.A.J. Rotherham \& C.R Hokanson, Jr. (eds.). Rethinking special education for a new century. Washington, DC: Thomas B. Fordham Foundation and Progressive Policy Institute, pp. 259-287

32. Mayes SD, Calhoun SL, Crowell EW (2000) Learning disabilities and ADHD: overlapping spectrum disorders. Journal of Learning Disabilities 33:417-424

33. Mc Cann BS, Roy-Byrne P (2000) Attention-deficit/hyperactivity disorder and learning disabilities in adults. Semin Clin Neuropsychiatry 5(3):191-7

34. McGillivray JA, Baker KL (2009) Effects of comorbid ADHD with learning disabilities on anxiety, depression, and aggression in adults. J Atten Disord 12(6):525-31

35. Mcleod S, Mckinnon DH (2007) Prevalence of communication disorders compared with other learning needs in 14,500 primary and secondary school students. Int $\mathrm{J}$ Lang Commun Disord 42(S1): 37-59

36. Mello CB de, Argollo N, Shayer BPM, Abreu N, Godinho K, Duran P, Vargem F, Muszkat M, Miranda MC, Bueno OFA (2011). Abbreviated Version of the WISC-III: Correlation between Estimated IQ and Global IQ of Brazilian Children [Versão Abreviada do WISC-III: correlação entre QI estimado e QI total em crianças brasileiras]. Psic.: Teor e Pesq 27(2):149-155

37. Mercadante MT, Asbahr F, Rosário-Campos MC, Ayres AM, Karman L, Ferrari MC, et al. K-SADS 3/4 Entrevista semi-estruturada para diagnóstico em psiquiatria da infância, versão epidemiológica. Quarta versão (Orvaschel H, Puig-Antich J, 1987) 
com permissão dos autores. São Paulo, SP: Protoc 3/4 Hospital das Clínicas da FMUSP; 1995.

38. Mogasale VV, Patil VD, Patil NM, Mogasale V (2012) Prevalence of specific learning disabilities among primary school children in a South Indian city. Indian J Pediatr 79(3):342-7

39. Ohlweiler L (2006) Transtornos da Aprendizagem. In: Rotta NT, Ohlweiler L, Riesgo RS (eds) Transtornos da Aprendizagem - Abordagem Neurobiológica e Multidisciplinar. Artmed, Porto Alegre, pp 124-130

40. Oliveira GE, Magalhães LC, Salmela LF (2011) Relationship between very low birth weight, environmental factors, and motor and cognitive development of children of 5 and 6 years old. Rev Bras Fisioter 15(2):138-45

41. Parliamentary Office of Science and Technology Dyslexia and Dyscalculia (2004) Scientific capacity in developing countries. London, UK: Post note, Number 226

42. Pastor PN, Reuben CA (2002) Attention Deficit Disorder and Learning Disability: United States, 1997-98. Vital Health Stat 10 (206):1-12

43. Pastor PN, Reuben CA (2008) Diagnosed attention deficit hyperactivity disorder and learning disability: United States, 2004-2006. Vital Health Stat 10 (237):1-14

44. Presidência da Republica do Brasil (1996) Diretrizes e Bases da Educação. Lei no 9.394, de 20 de dezembro de 1996. Disponível em: http://www.planalto.gov.br/ccivil 03/leis/l9394.htm

45. Rock EE, Fessler MA, Church RP (1997) The concomitance of learning disabilities and emotional/behavioral disorders: a conceptual model. J Learn Disabil 30(3):245-63

46. Rodriguez A, Järvelin MR, Obel C, Taanila A, Miettunen J, Moilanen I, Henriksen T, Pietiläinen K, Ebeling H, Kotimaa A (2007) Do inattention and hyperactivity symptoms equal scholastic impairment? Evidence from three European cohorts. BMC Public Health 7:327 
47. Rutter M, Caspi A, Fergusson D, Horwood LJ, Goodman R, Maughan B, Moffitt TE, Meltzer H, Carroll J (2004) Sex differences in developmental reading disability: new findings from four epidemiological studies. JAMA 291(16):2007-2012

48. Sanson A, Prior M, Smart D (1996) Reading disabilities with and without behaviour problems at 7-8 years: prediction from longitudinal data from infancy to 6 years. J Child Psychol Psychiatry 37(5):529-541

49. Sexton CC, Gelhorn HL, Bell JA, Classi PM (2012) The Co-ocurrence of Reading Disorder and ADHD: epidemiology, treatment, psychosocial impact, and economic burden. Journal of Learning Disabilities 45(6):538-564

50. Scerri TS, Schulte-Körne G (2010) Genetics of developmental dyslexia. Eur Child Adolesc Psychiatry 19(3):179-97

51. Shalev RS, Auerbach J, Manor O, Gross-Tsur V (2000) Developmental dyscalculia: prevalence and prognosis. Eur Child Adolesc Psychiatry 9: 58-64

52. Shastry BS (2007). Developmental dyslexia: an update. J Hum Genet 52(2):104-9

53. Silverstein AB (1985) Two-and four-subtest short forms of the WAIS-R: a closer look at validity and reliability. J Clin Psychol 41(1):95-7

54. Silverstein AB (1990) Short Forms of individual intelligence tests. Psychological assessment 2(1):3-11

55. Spencer T, Biederman J, Wilens T (1999) Attention-Deficit/Hyperactivity disorder and comorbidity. Pediatric Clinics of North America 46(5):915-927

56. Stein LM (1994) TDE: Teste de Desempenho Escolar - Manual para aplicação e interpretação. Casa do Psicólogo, São Paulo

57. Stough LM, Aguirre-Roy AR (1997) Learning disabilities in Costa Rica: challenges for an "army of teachers" J Learn Disabil 30(5):566-71 
58. Taanila A, Yliherva A, Kaakinen M, Moilanen A, Ebeling $H$ (2011) An epidemiological study on Finnish school-aged children with learning difficulties and behavioural problems. International Journal of Circumpolar Health 70(1):59-71

59. Tannock R (2012) Rethinking ADHD and LD in DSM-5: Proposed Changes in Diagnostic Criteria. J Learn Disabil 46(1):5-25

60. Tomblin JB, Zhang X, Buckwalter P, Catts $H$ (2000) The association of reading disability, behavioral disorders, and language impairment among second-grade children. J Child Psychol Psychiatry 41(4): 473-82

61. Unesco (2010) A organização para educação, ciência e cultura das Nações Unidas. Relatório sobre educação mundial da Unesco.

62. Veenstraa R, Lindenbergb S, Oldehinkelc AJ, Winterc AFDe, Verhulstd FC, and Ormelc J (2008) Prosocial and antisocial behavior in preadolescence: Teachers' and parents' perceptions of the behavior of girls and boys. International Journal of Behavioral Development 32(3):243-251

63. Von Aster MG, Shalev RS (2007) Number development and developmental dyscalculia. Dev Med Child Neurol 49: 868-873

64. Wajnsztejn AC, Wajnsztejn R (2005) Dificuldades escolares: um desafio superável. São Paulo: Artemis

65. Wechsler D (1991) Wechsler Intelligence Scale for Children - Third Edition (WISCIII); Figueiredo VLM (2002) Adaptação e Padronização de uma amostra Brasileira - Primeira Edição - São Paulo: Casa do Psicólogo

66. Whitsell LJ (1969) Learning Disorders as a School Health Problem - Neurological and Psychiatric Aspects. Calif Med 111(6): 433-445-791

67. World Health Organization (1993) The ICD-10. Classification of Mental and Behavioural Disorders: Diagnostic Criteria for Research. WHO, Geneva. 